\title{
CEsifo \\ WORKING

\section{Global Spillovers of Taxation in the Online Advertising Market. Theory and Evidence from Facebook}

Andrea Lassmann, Federica Liberini, Antonio Russo, Ángel Cuevas, Rubén Cuevas 


\section{Impressum:}

CESifo Working Papers

ISSN 2364-1428 (electronic version)

Publisher and distributor: Munich Society for the Promotion of Economic Research - CESifo

$\mathrm{GmbH}$

The international platform of Ludwigs-Maximilians University's Center for Economic Studies and the ifo Institute

Poschingerstr. 5, 81679 Munich, Germany

Telephone +49 (0)89 2180-2740, Telefax+49 (0)89 2180-17845, email office@cesifo.de

Editor: Clemens Fuest

https://www.cesifo.org/en/wp

An electronic version of the paper may be downloaded

- from the SSRN website: www.SSRN.com

- from the RePEc website: $\quad$ www.RePEc.org

- from the CESifo website: https://www.cesifo.org/en/wp 


\title{
Global Spillovers of Taxation in the Online Advertising Market. Theory and Evidence from Facebook
}

\begin{abstract}
We analyze the effect and welfare implications of taxing multinational digital platforms on the global online advertising market. Using a novel dataset on advertising prices and product preferences of users from Facebook in OECD countries, jointly with international trade data, we show that an increase in the platform's corporate tax rate in some countries had a strong effect on advertising prices therein. The increase spills over to other countries through pre-existing international trade linkages. This result is consistent with our theoretical model, which shows that a digital platform reduces the supply of ads to advertisers from countries where taxation increases.
\end{abstract}

JEL-Codes: H220, H250, F150, F230.

Keywords: online advertising, multi-sided platforms, tax incidence, product interests, international trade.

\author{
Andrea Lassmann \\ University of Mainz / Germany \\ andrea.lassmann@uni-mainz.de \\ Antonio Russo \\ Loughborough University / United Kingdom \\ a.russo@lboro.ac.uk
}

\author{
Federica Liberini \\ University of Bath / United Kingdom \\ fl571@bath.ac.uk \\ Ángel Cuevas \\ University Carlos III of Madrid \& UC3M- \\ Santander Big Data Institute / Spain \\ acrumin@it.uc3m.es
}

\author{
Rubén Cuevas \\ University Carlos III of Madrid \& UC3M- \\ Santander Big Data Institute / Spain \\ rcuevas@it.uc3m.es
}

April 28, 2020

We thank Johannes Becker, Greg Crawford, Mike Devereux, Irem Guceri, Bill Hoyt, Hans Jarle Kind, Marko Koethenbuerger, Niels Johannesen, Konrad Mierendorff, Philip Sauré, Joel Slemrod and audiences at Oxford, Darmstadt, ETH Zurich, the OECD, Kiel University, the 2017 MATAX Conference, the CESifo Digitization and Public Sector Economics Conferences, the CESifo Venice Summer Institute, the 2019 Annual Meeting of the German Economic Association Regional Science Committee, and the Workshop on Taxation and Regulation of the Digital Economy at NHH Bergen. We are grateful for financial assistance from the NET Institute. This paper previously circulated under the title "The Taxman calls. How does Facebook answer? Global Effects of Taxation on Online Advertising”. This work also received funds by: (i) the Ministerio de Economía, Industria y Competitividad, Spain, (ii) the European H2020 Project SMOOTH, (iii) the European H2020 Project PIMCity, and (iv) the Community of Madrid synergic project EMPATIA-CM. 


\section{Introduction}

Online advertising is a multi-billion dollar business and the main source of revenue for many of the companies currently at the forefront of the digital economy, such as Facebook, Google and Twitter. Worldwide online advertising spending currently amounts to more than 300 billion USD worldwide and is highly dynamic..$^{1}$ Given the fast digitization of the economy and the corresponding importance of the digital sector, rethinking the tax system

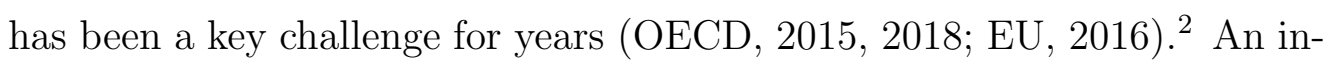
triguing aspect of this challenge is that many of the companies currently at the forefront of the digital economy are multi-sided platforms that operate worldwide and generate practically all of their revenue from online advertising ${ }^{3}$ These features set digital platforms apart from traditional firms, and imply that their response to taxation might also be substantially different (Rochet and Tirole, 2003, 2006; Kind et al., 2008). Our analysis addresses the worldwide implications of taxation for digital platforms and their users.

National governments have intensively discussed tax instruments directed at digital platforms, but they have implemented very few policies and failed to coordinate on a multilateral basis. A key issue in this respect is the lack of scholarly work on the topic, which - from an empirical viewpoint - is mostly due to difficulties in the collection of appropriate

\footnotetext{
${ }^{1}$ According to e-marketer, global digital advertising spending amounted to about 280 billion USD in 2018, and to about 330 billion USD in 2019. https://www.statista.com/statistics/237974/online-advertising-spendingworldwide/, last consulted on 14 April 2020.

${ }^{2}$ The U.S. Bureau of Economic Analysis estimated that real value added in the digital economy annually grew at 9.9 percent per year from 1998 to 2017 on average, compared to 2.3 percent for the overall economy. In 2017, this corresponded to $1.3 \mathrm{tr}$ USD in the US alone (equal half of the UK GDP and 6.9 percent of US GDP).

${ }^{3}$ We focus here on ad-financed platforms, such as search engines, social media, blogs, photo and video sharing and social discussion forums. The business model we refer to does not apply to platforms that operate as internet market places, like Amazon, as subscription services, like Netflix, or transaction intermediaries, like PayPal.
} 
data on the online advertising market. Bibler et al. (2018) provide to our knowledge the only other evidence of the effects of taxation on a digital platform, using AirBnB listings, but do not consider distributional effects of taxation. Also, theoretical work on the taxation of platforms (e.g., Kind et al., 2008) has not considered that digital platforms operate in multiple countries to date.

Our study makes several contributions to this literature. We start by collecting a unique panel data on daily online advertising prices from the world's largest social media, Facebook. We use this information to analyze the incidence of a change in corporate taxes in the market for advertising on social media. 4 To interpret the above evidence, we proceed with providing a novel theoretical model of a multinational digital platform, centered on the interplay between international taxation and the platform's multi-sided nature. The model shows that the platform's reallocation of the supply of ads across different national markets induces international spillovers. An additional contribution of our analysis is that we account for price spillovers due to advertising demand across countries. To proxy for this demand, we exploit novel information on the preferences for products of Facebook users in each country, together with international trade data. This aspect is crucial because information about user preferences is key to platforms that, like Facebook, match advertisers to users worldwide. Finally, we combine our model with innovative data on Facebook advertising quantities in a set of countries. This allows us to estimate overall welfare and distributional effects of taxation across countries.

Tax policies for the digital market should be evaluated taking into ac-

\footnotetext{
${ }^{4}$ Facebook has a market share of 80 percent in the social media market, according to the Digital Advertising Report 2019 - Social Media Advertising by Statista.com. In addition, Facebook's share in total global digital advertising revenue amounted to nearly 20 percent (Figure A1). In 2018, the social media advertising market generated a worldwide revenue of $\$ 76.2$ billion, representing the second largest digital advertising market. https://www.statista.com/study/36294/digital-advertisingreport-social-media-advertising/, last consulted on January 17, 2019.
} 
count the distinctive features of multi-sided platforms compared to traditional firms. Most importantly, platforms bring together markets connected by externalities, such as the market for digital content and the market for advertising (Rochet and Tirole, 2003). Advertisers value being able to reach large audiences browsing the platform's content, while users may not like being exposed to ads. These externalities are likely to drive the platforms' response to international taxation, including how they adjust ad prices within and across different countries. Besides, the importance of understanding the pass-through of costs when firms have market power transcends tax policy (Weyl and Fabinger, 2013).

We exploit a recent change in Facebook's accounting practices, which resulted in an increase in the firm's corporate tax rate in many countries. Facebook generates more than 98 percent of its revenue from advertising, hence the effect of changes in profit taxes is likely to produce effects comparable to taxes on advertising revenue. Using panel and spatial models, we estimate the effect that an increase in the tax rate has on the median of daily unit prices of ads targeted at country-specific audiences of Facebook users located in member countries of the Organisation for Economic Co-operation and Development (OECD). Our period of observation is between July 2015 and February 2017. The tax increase affected a subset of countries, namely ones in which Facebook has a sales office, and advertising prices increased sharply in those countries. Our results show a sizeable effect of increasing the tax rate on the prices of ads to Facebook audiences. We estimate that the price (measured per thousand impressions) increased on average by $\$ 0.09$ to $\$ 0.29$ following Facebook's accounting restructuring, which translates to about 10 to 32 percent of the average price before the restructuring. While the impact on prices for countries affected by the tax change is stronger (about 35 percent of the initial price), prices also rose in countries exempt from the change (about 26 percent of the initial price). 
The empirical findings are consistent with our theoretical model of an ad-financed platform that operates in several countries. In this model, users in each country are exposed to ads from local and foreign advertisers. While users access the platform for free, ads reduce the users' surplus from browsing its content (Anderson and Coate, 2005). Hence, the platform limits the supply of ads to each audience. When the profit tax rate in a country increases, the platform reallocates some of the ad supply from advertisers in that country to the others. This reallocation increases the prices charged to advertisers from countries in which the tax goes up (regardless of the audience they target), whereas prices to advertisers from the other countries decrease. Similar effects would be at play in the case of indirect taxes on the platform's revenue (e.g., ad valorem taxes on ad sales).

Our theory suggests that a digital platform responds to taxation by reallocating the supply of ads and adjusting their prices across countries. In practice, these adjustments interact with demand-side forces stemming from pre-existing international trade linkages. In the empirical analysis, we capture these forces by combining data on product preferences of Facebook users (reported by the platform) with data on international trade. To understand why it is relevant to incorporate this information, let us consider two countries, $a$ and $b$. The multinational platform finances its operations by linking users and advertisers both within and across $a$ and $b$. Thereby the demand and price for ads to users in both countries depend on which products these users are interested in, and on the share of the market for such products that belongs to $a$ - and $b$-based firms. By incorporating product preferences, we are able to account for the relevance of different products in the demand for advertising on Facebook across countries (see also Linder, 1961; Fajgelbaum and Khandelwal, 2016). Our empirical approach draws on recent evidence that prices and trade flows 
in digital markets are highly correlated with traditional markets (Cavallo, 2017, Lendle et al., 2016) $!^{5}$

To give a sense of the economic relevance of the effects we estimate, we provide an approximate calculation of the pass-through of profit taxation on advertising prices. The results of this exercise are quite sensitive to the model specification and to the tax rate that the platform pays in Ireland. Our baseline estimates suggest overshifting of taxes on ad prices. The magnitude is comparable to previous estimates of VAT pass-through on the prices of consumer goods and services (Benedek et al., 2015).

Finally, we calibrate the model using our data, and provide a welfare analysis of the tax change in several countries. The net effect of the tax change on total welfare is small, but interesting changes surface in the distribution of surplus. Because of the increase in ad prices, taxation tends to penalize advertisers in countries affected by the tax increase and benefit advertisers in those where taxes remain unchanged. On the other hand, consumers are slightly better off regardless of their location, given that the platform reduces the provision of ads overall.

Our work is a first exploration of the effects of taxation on multi-sided digital platforms and the sources of spillovers thereof. The analysis suggests that decentralized tax policies may influence the price and distribution of ads across countries, even in countries where tax policy does not change. Therefore, the effects of taxes may extend beyond the allocation of accounting profits (e.g., through transfer pricing) in ways that signal a departure from the dynamics associated with traditional multinational enterprises. Policymakers should carefully evaluate the potential consequences of taxes on digital platforms on i) the level and distribution of ads and prices across

\footnotetext{
${ }^{5}$ Note that in previous literature, trade-related tax spillovers are examined from a macroeconomic perspective (e.g., Frenkel et al., 1990; Auerbach and Gorodnichenko, 2013). By contrast, they stem from direct trade patterns in our setting. In Section 5.4 we will also employ the gravity model of trade, which is typically used to describe the patterns of trade.
} 
different audiences and ii) the price spillovers due to the global advertising network. In the context of ad hoc tax systems for the digital economy, our findings provide some support to the idea of attributing shares of created values to the location of consumers rather than that of advertisers.

We organize the remainder of this paper as follows. In the next section, we briefly describe how our paper relates to the existing literature on the taxation of digital platforms. We then discuss the policy climate and Facebook's accounting restructuring, in section 3. Section 4 introduces our data and illustrates some preliminary evidence. This section also provides a theoretical framework for interpreting our preliminary evidence. This is complemented by the empirical analysis of section 5 . Section 6 provides the welfare analysis and the final section concludes.

\section{Relation to previous literature}

A growing theoretical literature on taxation in two-sided markets underscores that the effects of taxation in such markets are likely to differ from those in traditional ones. Kind et al. (2008) show that ad valorem taxes may result in lower prices and increased service provision by a platform. Belleflamme and Toulemonde (2018) show that taxes may result in competing platforms making higher profits. Part of this literature focuses on how taxation may complement regulatory policy regarding data collection by digital platforms. Bourreau et al. (2018) study the implications of taxing data and ads on a digital platform, while Bloch and Demange (2018) consider how taxation may affect a platform's incentives to collect and exploit users' personal data. Most of the literature ignores the presence of multiple jurisdictions, with the exception of Kotsogiannis and Serfes (2010). However, their approach is significantly different from ours. They model competing jurisdictions as two-sided platforms that strive to attract 
consumers and shops.

Our paper contributes to the above literature in several ways. First, we analyze profit taxation, rather than commodity taxes. In our model, profit taxes applying to a multinational platform have similar effects as ad valorem commodity taxes. Secondly, we consider a platform that operates in a multinational context. The platform internalizes the interactions that link not only different markets within a single country (e.g. content and advertising), but also markets in different countries. As a result, the platform can respond to taxation along several dimensions. For instance, it can reallocate the supply of ads, and adjust their price across multiple countries.

Taking a broader perspective, our paper relates to the literature studying the effects of regulation in two-sided markets (Anderson and Coate, 2005; Rochet and Tirole, 2003, 2006). Recent papers include Economides and Hermalin (2012), who analyze the implications of net neutrality regulation for the internet, and Bedre-Defolie and Calvano (2013), who study regulation of payment platforms. We focus on fiscal rather than regulatory policy.

The empirical literature on two-sided markets has so far focused on the implications of market power and inter-market externalities, ignoring taxation. Examples include Argentesi and Filistrucchi (2007), who provide an analysis of competition and prices in the Italian newspaper industry. Wilbur (2008) and Boik (2016) analyze the US television industry, whereas Jeziorski (2014) provides evidence from the US radio industry. In a recent survey, Kind and Moen (2015) point out a need for empirical evaluation of the effects of taxes and subsidies in two-sided markets. A key novelty of our paper is to provide this kind of evidence from a dominant multinational digital platform (MDP) in the online advertising market. To our knowledge, the only other paper providing evidence of the effects of taxation on a 
digital platform is Bibler et al. (2018). The authors use data from AirBnB listings to investigate the magnitude of hotel and tourism tax evasion and the incidence of these taxes on rental rates.

\section{Facebook's accounting restructuring and the policy climate}

Our analysis exploits a recent change in Facebook's accounting regime. Until 2016, the company booked all non-US advertising sales through its Irish subsidiary, irrespective of the advertisers' location and of that of their target audience. In the spring of 2016, Facebook announced that UK advertising sales would be booked locally. This change is illustrated in Figure

1.

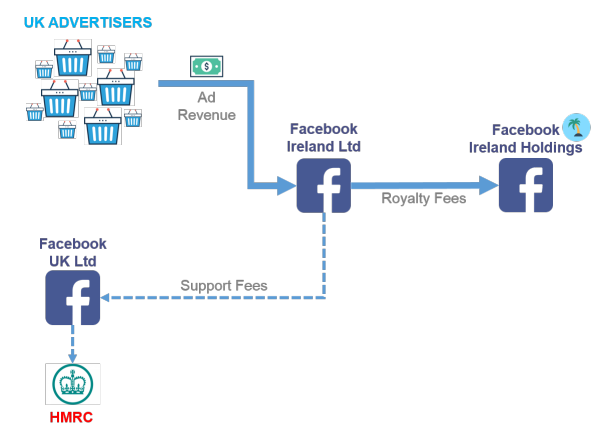

(a) Before change

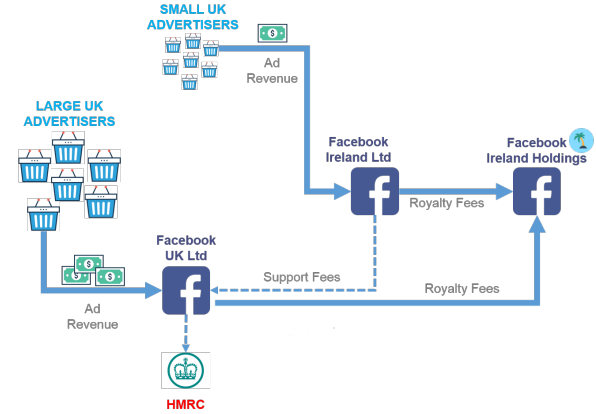

(b) After change

Figure 1: Implications of Facebook accounting reform in March 2016

In late 2017, it indicated that the same change would also apply to all other countries hosting one of the firm's sales offices, hence at present, Facebook books advertising sales locally in all countries hosting one of its sales offices. That is, Facebook bills advertisers located in sales-office (SO, henceforth) host countries, regardless of the location of the advertisers' target audience. The SO countries are: Australia, Belgium, Canada, France, Germany, Israel, Italy, Japan, the Netherlands, New Zealand, Norway, Poland, 
Spain, Sweden, the UK and the US. This restructuring began in March 2016, when Facebook announced it would start booking its UK advertising sales locally: ${ }^{6}$ In December 2017, Facebook revealed that similar changes would take effect in all the other SO countries.

Given the accounting restructuring and the relevance of ad revenues to Facebook's total revenues, changes in advertising revenue collected in an SO country directly affect that country's Facebook tax base. This is relevant, because the marginal tax rate that Facebook pays in $\mathrm{SO}$ countries, which matters for the allocation and pricing of ads, is arguably higher than the tax rate paid in Ireland. The statutory corporate tax rate in SO countries averages 25.9 percent, versus the Irish statutory 12.5 percent. The difference in the effective tax rates may be larger, because Ireland's tax regime is quite favorable to multinational companies. While Facebook may adopt similar practices in other countries as well, the cost of eroding the tax base is arguably higher due to less favorable tax rules.7 Therefore, Facebook's restructuring corresponds to an increase in the marginal tax rate on its advertising revenue in $\mathrm{SO}$ countries. Our analysis of the effects of taxation on advertising prices is based on this premise 8

Facebook's accounting changes took place in the midst of several tax policy reforms. The global discussion about possible future multilateral collaboration on taxing digital markets had begun, and it continues to evolve and garner greater policy attention. The OECD recently directed an important discourse on reforming taxation for the digital economy, based on

\footnotetext{
${ }^{6}$ This change affected large advertisers, to which Facebook provides advertising as well as ancillary services. These advertisers are a relatively small share of the total population of advertisers on Facebook, but account for most of the ads and revenue. Small advertisers would instead continue receiving invoices from Facebook Ireland Ltd.

${ }^{7}$ For instance, Ireland allows the payment of peculiarly large royalty fees to subsidiaries located in tax havens (e.g., the Cayman Islands). See, e.g., CNN.com "How Apple paid just 0.005 percent tax on its global profits", August 31, 2016.

${ }^{8}$ Because Facebook's US revenue was booked locally even before the restructuring, we do not include the US in the group of SO countries when we measure the effect of tax changes on the price of ads.
} 
the Base Erosion and Profit Shifting Action Plan.$^{9}$ More recently, the European Commission unveiled plans to allow member states to tax profits generated in their territory based on a "digital presence," defined by volume of revenue (larger than 7 million euros), number of users (more than 100,000), or number of business contracts for digital services (more than $3,000)$. Because this project requires complex reforms, the Commission has also set the short-term goal of an interim tax that "covers the main digital activities that currently escape tax altogether in the EU." This tax would apply to revenue from advertising as well as sales of user data.

In addition to ongoing efforts to design multilateral policy instruments, a number of individual countries, particularly in Europe, have shown interest in raising taxation on MDPs. Most importantly, effective April 2015, the UK introduced the diverted profit tax, which imposed a punitive 25 percent profit tax rate for companies that shift profit out of the country (in place of the standard rate of 20 percent). Several reports indicate that the establishment of this new tax, which the company would have been liable to pay had it continued booking advertising sales in Ireland, was a relevant factor 10 The DPT was quickly renamed "Google tax" by the media, despite applying to all multinationals ${ }^{11}$ The Australian government an-

\footnotetext{
${ }^{9}$ See https://www.oecd.org/tax/beps/public-consultation-documentsecretariat-proposal-unified-approach-pillar-one.pdf.

${ }^{10}$ See The Financial Times "Facebook faces profits hit after tax shake-up.", March 4th 2016 and The Guardian "Facebook to stop routing ad revenue via Ireland amid pressure over taxes", 12 December 2017. The former article quotes a Facebook staff memo claiming that "In light of changes to tax law in the UK, we felt this change would provide transparency to Facebook operations in the UK". Similar statements were reported in the press also regarding other SO countries. See, e.g., Politico.eu "Facebook to overhaul how it pays tax worldwide", December 12, 2017 and Bloomberg.com "Facebook to Pay More Tax in France", April 29th 2019. We empirically accommodate potential anticipation of further tax reforms later on.

${ }^{11}$ The declared purpose of the diverted profit tax is "to counteract contrived arrangements used by large groups (typically multinational enterprises) that result in the erosion of the UK tax base." A typical example where liability for such a tax may arise is that of a non-UK company with an Irish subsidiary that provides services to UK customers, while being only partially supported by a UK assisting subsidiary. In this example, the authorities might impose the tax to the Irish principal for diverting profits generated in
} 
nounced the introduction of a similar DPT, effective July 2017, imposing a rate of 40 percent on diverted profits (the standard rate being 30 percent). Italy, France and Germany have opened investigations for the collection of back taxes from MDPs. For example, France approved a "digital services tax" in 2019, and is working with Germany to implement the EU's proposal for an interim tax by 2021. Other countries, including Israel, India and the Slovak Republic, have introduced ad hoc tax rules for firms with "significant economic presence" in their country. See Table 1 for a summary of the policy initiatives.

Table 1: TAX REForms AFFECting Digital Platforms in OECD COUNTRIES

\begin{tabular}{|l|l|l|}
\hline \hline Country & Intervention & Year \\
\hline & & \\
GER, ITA, FRA, UK & Repayment of Back Taxes & $2014 / 2017$ \\
UK, AUS & Diverted Profit Tax (25\%) & $2015 / 2016$ \\
ISR & Tax for "Significant Economic Presence" & 2016 \\
TUR & Withholding Tax on E-payments & 2016 \\
HUN & Advertisement Tax & 2018 \\
AUT & Online Advertisement Tax & 2018 \\
FRA & 'YouTube' Tax & 2018 \\
SVK & Intermediation Tax & 2018 \\
FRA & 'Google-Apple-Facebook-Amazon' tax & 2019 \\
ITA & New Web Tax (3\%) & Ongoing \\
NZL & Digital Services Tax & Ongoing \\
EU (Short Term) & Interim Tax on ad revenue and online sales & Ongoing \\
EU (Long Term) & Tax based on "digital presence" & Ongoing \\
\hline \hline
\end{tabular}

\section{Preliminaries}

\subsection{Facebook advertising prices}

With a base of over 2 billion active users and a global penetration rate of 27 percent, Facebook is the largest social media platform worldwide.

the UK. 
The platform gathers practically all of its revenue from the sale of ads (or "impressions") ${ }^{12}$ Facebook classifies users based on a set of observable characteristics (e.g., demographics, interests, etc.). A user connecting to the platform generates impression opportunities that are sold to advertisers via online auctions, conducted virtually in real time. Advertisers' bids for these impressions depend on the user's characteristics (see Appendix F for a more detailed description of Facebook's auction system). Advertisers located in any country can send ads to both domestic and foreign Facebook users.

Our empirical analysis relies on a panel database of prices for ads directed at Facebook audiences in all OECD countries. We collected these prices from Facebook's Ad Manager website at a daily frequency from July 2015 to February 2017. Specifically, we observe the median of the range of prices that, according to Facebook, are currently being paid for ads to the selected audience. Henceforth, we refer to such value as the median price for an audience (see Section 5.2 for further details).

In light of the large number of auctions for impressions that take place daily, it is reasonable to think of the median price as a weighted average of prices paid for an audience, with weights given by the relevance of each group of advertisers in the advertising demand for that audience. It is important to note that the median price we observe for each audience is representative of the distribution of prices paid by all advertisers that send ads to such audiences, including domestic and foreign ones. Hence, the median prices are interconnected across countries. For instance, the median price for a non-SO country audience may be affected by changes in the way Facebook treats advertisers from SO countries targeting the same audience.

\footnotetext{
${ }^{12}$ Figures reported by Nasdaq indicate that between 2016 and 2018, the company generated from $\$ 27$ billion to $\$ 55$ billion in worldwide advertising, a contribution to total revenue equal to 97.3 percent and 98.5 percent, respectively, in those years.
} 


\subsection{Preliminary evidence}

To identify the effects of taxation on advertising prices, we exploit the change in Facebook's accounting structure described above. We define the break point in the price distribution over time for all countries as March 7, 2016. Facebook's accounting restructuring formally started with the UK, but the company very likely anticipated that it would implement such restructuring in other $\mathrm{SO}$ countries as well.

Figure 2 plots the unconditional median prices as measured by cost per thousand or cost per mille (CPM), a marketing term that expresses the price of 1,000 advertisement impressions on one webpage. The figure shows the median CPM in countries where Facebook has a sales office (red line) and where it does not (blue line)13 In addition, we separately illustrate the development of ad prices in the UK. The figure shows that after the restructuring the median price increased substantially in both SO and non-SO countries. However, the intensity of the change appears to be weaker in the non-SO countries.

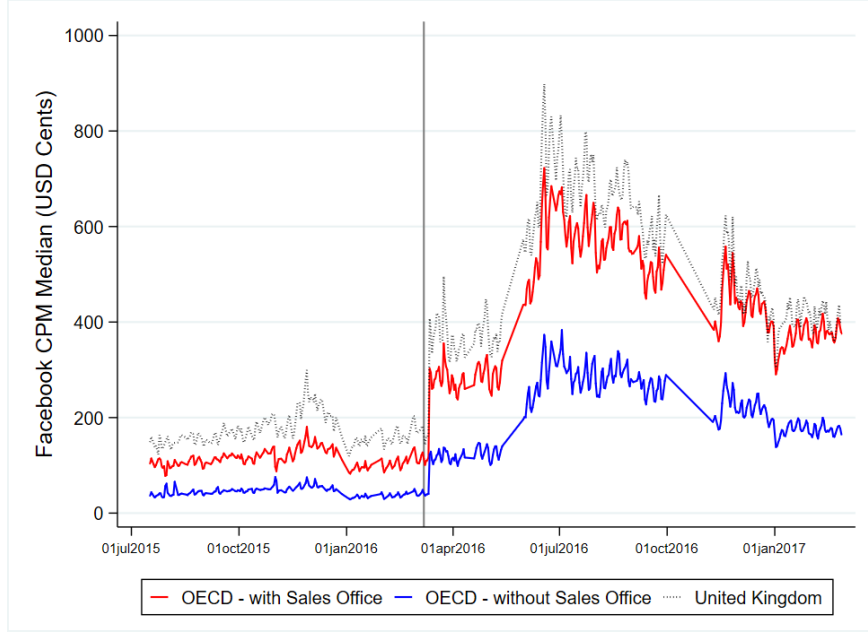

Figure 2: MEDIAN CPM, AVERAGE FOR OECD COUNTRIES

An immediate concern is that the observed shift in prices could be

\footnotetext{
${ }^{13}$ CPM stands for Cost-Per-Mille, i.e. price per thousand impressions. This is the most commonly used metric to describe online advertising prices.
} 
due to country- specific characteristics, or events that are unrelated to the tax implications of Facebook's accounting restructuring. To rule out these possible confounding factors, we regress the median prices on country fixed effects and time dummies that account for seasonality and relevant events (e.g., holidays, elections, and relevant global events) that took place in 2016. ${ }^{14}$ To capture possible shocks to online advertising prices outside Facebook, we also control for the prices of online ads in the US (averages across the whole internet). Figure 3 plots the residuals of this regression, distinguishing between SO countries (red line) and NS countries (blue line). plots the residuals of this regression, distinguishing between SO countries (red line) and NS countries (blue line). The figure shows that the changes observed in Figure 1 are not explained by the above confounding factors for non-SO countries. However, a pronounced difference exists between the behavior of median prices in SO and non-SO countries.
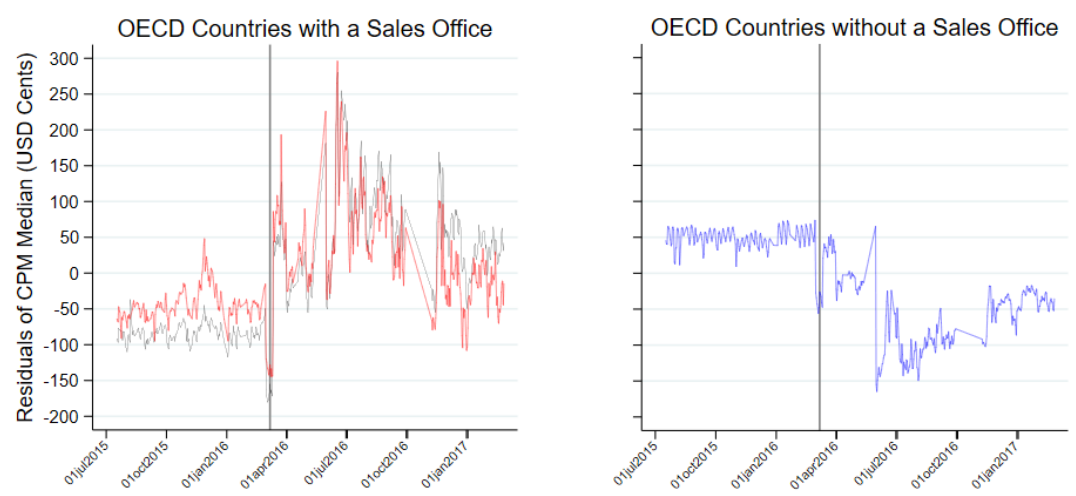

Figure 3: MEDIAN CPM (RESIDUAL), OECD COUNTRIES

Note: residuals from linear regression of CPM Median levels on country fixed effects, day of the week, holidays, election shopping event dummies and a monthly trend.

In Appendix B, we also show results from a VAR analysis indicating that we can significantly reject the null hypothesis of no break around the

\footnotetext{
${ }^{14}$ Among others, we control for the Brexit referendum, for the US elections, and "Black Friday".
} 
date of announcement of Facebook's restructuring. These figures suggest that the effect is not only significant statistically and economically, but it is also heterogeneous across countries.

It is, of course, possible that the change in accounting practices announced on March 7, 2016, coincided with some other change that affected the price of ads on Facebook that we do not observe (e.g., changes in the algorithms that match users to advertisers). An extensive search did not uncover information about any such changes. Facebook formally announced its decision to restructure accounting practices in a press release. The media extensively covered the decision. To our knowledge, no report about other major modifications to Facebook's ad pricing or allocation took place at the same time.

The evidence presented thus far suggests that (i) the effective increase in taxes on the revenue collected in SO countries coincided with an increase in advertising prices on Facebook and (ii) the change also affected the prices of non-SO audiences, although the effect appears to be substantially smaller than on prices of SO audiences. Our hypothesis is that these price spillovers are caused by the global nature of Facebook's advertising market. We test this hypothesis below and evaluate the implications of these interconnections theoretically and empirically.

\subsection{Theoretical model}

Consider a digital platform operating in two countries. The platform provides free content to consumers and sells impressions to advertisers. Let $n_{j}$ be the (exogenous) quantity of advertisers located in country $j=1,2$. Advertisers within a country are identical. The platform sells impressions to advertisers in country $j$ via its local subsidiary. We assume the subsidiary in $j=2$ (the "low-tax" country) is not subject to corporate taxes, whereas that in $j=1$ (the "high-tax" country) pays a tax $t>0$. Drawing 
from our empirical setting, one can think of Country 1 as a SO country and Country 2 as a non-SO country, whereby Facebook's advertising revenue is booked in Ireland and thus is virtually untaxed. Figure 4 provides a graphical representation of the setting.

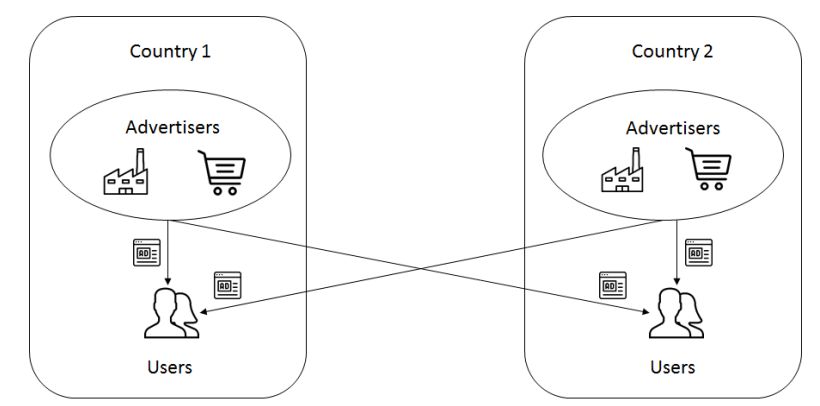

Figure 4: MARKET STRUCTURE

Let $z_{i}\left(q_{i}\right)$ be the quantity of users in country $i$ that connects to the platform and $q_{i j}$ the quantity of ads that an advertiser from $j$ sends to a user in country $i$. A user in country $i$ is exposed to $q_{i}=\sum_{j=1,2} n_{j} q_{i j}$ total ads. Throughout the analysis, we shall use the index $j$ to denote the location of advertisers, whereas $i$ shall denote the location of users.

In keeping with previous literature (e.g., Anderson and Coate, 2005), we assume that ads reduce the utility consumers get from browsing the platform's content, hence $z^{\prime}()<$.0.15 To ensure that sufficient conditions for a unique solution to the platform's profit maximization problem are satisfied, we also assume that $z^{\prime \prime}() \leq$.0 .

Let $p_{i j}\left(q_{i j}\right)$ be the willingness to pay for an additional ad on a consumer located in $i$ by an advertiser located in $j$, given the advertiser sends $q_{i j}$ impressions to this consumer. We assume $p_{i j}^{\prime}()<$.0 , as the marginal value of impressions on a consumer is decreasing. ${ }^{16}$ Observe that $p_{i j}\left(q_{i j}\right)$ does not

\footnotetext{
${ }^{15}$ Although digital technologies can improve the relevance of digital ads to users (e.g., through better targeting), these ads are generally annoying. This observation is confirmed by the increasing diffusion of ad blockers and the fact that several digital publishers offer ad-free versions of their websites for a price (e.g., YouTube Red).

${ }^{16}$ For example, one can assume the purpose of ads is to inform consumers about
} 
depend on the quantity of ads the advertiser places on other consumers (in particular, those located in a country different than $i$ ).

We assume advertising quantities, $q_{i j}$, are the platform's decision variables, with $i, j=1,2$. In equilibrium, $p_{i j}=p_{i j}\left(q_{i j}\right)$ holds, where $p_{i j}$ is the price per impression paid by an advertiser in $j$ to reach an audience in $i$. In other words, the platform adopts third-degree price discrimination, as advertisers from different countries may not pay the same price to reach a given audience. We discuss these assumptions below.

The platform sustains no variable costs, which is fairly realistic for providers of digital content. Thus, its profit is

$$
\pi=\sum_{i=1,2} z_{i}\left[n_{1} q_{i 1} p_{i 1}(1-t)+n_{2} q_{i 2} p_{i 2}\right]
$$

For simplicity, we ignore the possibility that the platform reduces its tax liability in a country by manipulating accounting profits (e.g., by paying royalty fees to low-tax subsidiaries). This assumption is not crucial. We could model such within-firm payments as lump-sum transfers between subsidiaries, possibly including costs that increase with the size of these transfers (as in, e.g., Devereux et al., 2008). As long as the taxable revenue in the high-tax country is positive, our results are qualitatively unaffected, because the marginal effective tax rate is what matters for the allocation of ads. If the effective tax rate increases with $t$, the effects on the price and quantity of ads are essentially the same as what we obtain.

The first-order conditions (FOCs) of the platform's problem with re-

products. The more a consumer is exposed to an ad, the higher the probability that the marginal impression is wasted, because the consumer is already aware of the advertised product. This assumption is in line with the media economics literature. (See, e.g., Ambrus, Calvano and Reisinger, 2016.) 
spect to the quantity of ads directed at country $i=1,2$ are

$$
\begin{gathered}
\frac{\partial \pi}{\partial q_{i 1}}: n_{1}\left[(1-t)\left(z_{i}\left(p_{i 1}+\frac{\partial p_{i 1}}{\partial q_{i 1}} q_{i 1}\right)+z_{i}^{\prime} n_{1} q_{i 1} p_{i 1}\right)+z_{i}^{\prime} n_{2} q_{i 2} p_{i 2}\right]=0 \\
\frac{\partial \pi}{\partial q_{i 2}}: n_{2}\left[z_{i}\left(p_{i 2}+\frac{\partial p_{i 2}}{\partial q_{i 2}} q_{i 2}\right)+z_{i}^{\prime} n_{2} q_{i 2} p_{i 2}+(1-t) z_{i}^{\prime} n_{1} q_{i 1} p_{i 1}\right]=0
\end{gathered}
$$

The left hand sides of the expressions in (2) and (3) are the marginal revenues from impressions sold to advertisers from country $j=1,2$, respectively, that target users in country $i$. These expressions include the mechanical effect due to the expansion in the volume of ads and the ensuing reduction in the equilibrium price. Furthermore, there is a negative effect on revenue due to the reaction of $i$ 's consumers to the change in the level of advertising they are exposed to. Note that this effect reduces the revenue generated by advertisers located in $j$ as well as in the other country, as captured by the last term in (2) and (3). Thus, there is an implicit cost of exposing an audience to a greater quantity of ads. Notice that, as taxation affects only the revenue collected from advertisers of country 1, it makes the implicit cost of ads allocated to such advertisers relatively larger.

Observe that the FOCs in (2) and (3), that refer to country $i$ 's audience, are independent of the quantity of ads the platform shows to the audience in the other country. The reason is twofold. First, users in country $i$ only care about the total quantity of ads, $q_{i}$ they are exposed to, but not about the quantity of ads the platform shows to users in the other country. Furthermore, an advertiser's demand for ads to $i$ 's audience does not depend on the quantity of ads the advertiser sends to the other audience.

We now analyze the effect of changes in $t$ on the quantity and price of ads carried by the platform. Using (2) and (3), we can show (see Appendix 
C) that

$$
\frac{\partial q_{i 1}}{\partial t}<0, \frac{\partial q_{i 2}}{\partial t}>0, i=1,2
$$

which implies directly that

$$
\frac{\partial p_{i 1}}{\partial t}>0, \frac{\partial p_{i 2}}{\partial t}<0, i=1,2
$$

Therefore, the quantity of impressions per consumer sold to advertisers from country 1 decreases with the tax rate applied in country 1, while the price of these impressions increases. The opposite applies to impressions sold to advertisers from country 2. The intuition is easily grasped from (2) and (3). Consumers dislike advertising, so the platform must limit the quantity of ads it exposes each consumer to. That is, the supply of ads on each consumer is effectively limited. Therefore, the platform has to allocate this supply between advertisers from country 1 and 2 . When the profit tax in 1 increases, the marginal revenue from ads sold to advertisers therein decreases. Hence, the platform reallocates the supply of ads to advertisers in 2: $q_{i 1}$ decreases while $q_{i 2}$ increases. Advertisers from country 1 thus pay a higher price following the tax increase, contrary advertisers from country 2 .

Notice that this outcome is a consequence of the two-sided nature of this market. If users did not care about being exposed to ads (i.e. $z^{\prime}=0$ ), taxation would have no effect on prices and quantities, as (2) and (3) show.

Proposition 1 An increase in profit taxation in one country causes higher prices to advertisers located therein and lower prices to advertisers in the other country, regardless of the audience they target.

Before proceeding, we briefly discuss the assumption that the platform controls the allocation of ads to advertisers of different countries, $q_{i j}$. The sale of ads on Facebook takes place via auctions, but there are ways for the 
platform to influence their allocation. For example, Facebook assigns scores to advertisers based on the relevance of their message to the audience they target. This scoring affects their probability of winning the auctions. The score depends on the advertiser's location, among other things ${ }^{17}$ Hence, adjusting such a score allows the platform to influence the allocation of impressions across countries. By the same token, the platform can influence the equilibrium prices paid by advertisers from different countries. Therefore, advertisers in different countries can pay systematically different prices for reaching the same audience. See Appendix $\mathrm{F}$ for details on Facebook advertising auctions.

Proposition 1 suggests that advertisers from SO countries (i.e., those where Facebook's revenue is taxed at higher rate following the restructuring) should pay higher prices regardless of which audience they target, contrary to the situation faced by advertisers from non-SO countries. To connect this result to the preliminary evidence of Section 4.2 , recall that the median prices we observe are defined by location of the audience. Specifically, they are the median of the range of prices for audience $i$ paid by advertisers from each country $j$. We treat them as a weighted average of the prices, $p_{i j}$, paid by such advertisers.

Given Proposition 1, the increase in the median price for audience $i$ following the restructuring is more likely to be positive the larger the share of the demand for ads to such audience that originates from $\mathrm{SO}$ countries. If an audience is exposed primarily to domestic ads, one can expect the median price to increase when the audience is located in a SO country, and to decrease if the audience is in a non-SO country. However, a larger share of demand coming from foreign advertisers located in SO countries should make a positive effect more likely. This reasoning is consistent with our

\footnotetext{
${ }^{17}$ See https://www.facebook.com/business/help/430291176997542?helpref= faq_content.
} 
preliminary evidence, which shows that Facebook's accounting restructuring coincided with an increase in advertising prices to all audiences (Figure 2), but that the effect for the prices to SO audiences was significantly different than that for audiences in non-SO countries (Figure 3). Section 5 provides a more formal treatment of this issue.

\section{Empirical analysis}

\subsection{Empirical Strategy}

Section 4.2 suggests that changes in taxation within one country can affect the price of ads targeted at audiences located in other countries, consistently with our theoretical model. The key reason for the interaction between the median ad prices is that they are defined by location of the audience, but a country's audience is typically exposed to ads from domestic as well as foreign advertisers. Consequently, to identify the response of our median ad prices to the increase in taxation on Facebook's revenue in SO countries, we need to address spillovers across countries ${ }^{18}$ To model the international network of ad markets, we rely on the link between digital and physical markets. Our approach is inspired by recent macroeconomic and international economics literature, showing that prices and trade flows in digital and traditional markets are highly correlated (Cavallo, 2017; Lendle et al., 2016).

Our strategy can be described as follows. Consider a group of $N$ countries. The share that advertisers from country $j=1, \ldots, N$ have in the demand for ads sent to an audience in country $i=1, \ldots, N$ should be explained by the share that firms from country $j$ have in country $i$ 's market for products

\footnotetext{
${ }^{18}$ Previous literature has shown that fiscal policy changes may affect outcomes in other countries through international trade (e.g., Beetsma et al., 2006; Auerbach and Gorodnichenko, 2013; Goujard, 2017). More generally, this idea is also consistent with fiscal shocks being transmitted through the current account at the macroeconomic level.
} 
and services that are likely to be advertised on Facebook. More precisely, we assume advertisers from $j$ account for a share of the demand for ads directed at $i$ 's audience that depends on two factors: The first is which products the audience in $i$ cares about. Such product preferences proxy for the likelihood that a product is advertised to audience $i$ on Facebook given differences in expenditure shares ${ }^{19}$ For instance, electronic devices are probably more likely to be advertised on Facebook than lumber or natural gas. The second factor is the share of the market for such products in country $i$ accruing to suppliers from $j$. To capture these factors, we combine data on Facebook user interests with international trade data.

Formally, we assume that the price for an audience in country $i$ at date $d$ can be expressed as a weighted average

$$
p_{i d}=\sum_{j \neq i} w_{i}^{j} p_{i j d}+w_{i}^{i} p_{i i d}, \quad i=1, \ldots, N
$$

where $p_{i i d}$ and $p_{i j d}$ indicate the price that, respectively, domestic and foreign advertisers pay at $d$ to target audience $i 20$ The weight of advertisers from any country, $w_{i}^{j}$, is time invariant and approximated by the share of the demand for ads targeting audience $i$ from advertisers located in country $j$, $A d s_{i}^{j}$ :

$$
w_{i}^{j} \sim A d s_{i}^{j}
$$

Although we do not observe $A d s_{i}^{j}$ directly, we can proxy for these vari-

\footnotetext{
${ }^{19}$ The measurement of these is also consistent with the demand-side focus of this approach. Note that we take the trade network as given in this paper, i.e. we are not interested in the prediction of trade flows (e.g., Linder, 1961). Note also that our approach does not directly relate to the literature on non-homothetic preferences (e.g., Fajgelbaum and Khandelwal, 2015.), as we are controlling for income differences by way of country fixed effects and the inclusion of GDP.

${ }^{20}$ This is similar to the construction of world relative demand (eq. 15) in Frenkel et al. (1990).
} 
ables using international trade flows averaged across sectors. To compute proxies for the weights of foreign advertisers in country $i$, we average manufacturing imports into $i$ from each country $j$ across product categories, Trade $_{i j k}$ (where $k$ is the index for an HS 4-digit category), weighted by product penetration rates, $\mathrm{FCBKPen}_{i k}{ }^{21}$ In a nutshell, these penetration rates measure the share of the audience in $i$ that is interested in product $k$. We derive this information from data reported by Facebook (see Section 5.2 for a more detailed description). We thus approximate the weights in eq. (7) as follows. Let $g(\cdot)$ be a continuously differentiable and increasing function. Then

$$
w_{i}^{j} \sim \omega_{i}^{j}=g\left({\widetilde{\operatorname{Trade}_{i j}}}_{/ \sum_{j}}{\widetilde{\operatorname{Trade}_{i j}}}_{i}\right), \quad j=1, \ldots, N,
$$

where

$$
{\widetilde{\operatorname{Trade}_{i j}}}_{i}=\sum_{k} \mathrm{FCBKPen}_{i k} \times \operatorname{Trade}_{i j k} .
$$

We do not construct the same proxy for the weight of domestic advertisers in country $i, w_{i}^{i}$. Standard international trade data do not report information on domestic consumption by product category in each country. ${ }^{22}$ Consequently, we do not control directly for an audience's exposure to domestic advertisers in the empirical model. However, we account for such exposure in the analysis in the next section.

\footnotetext{
${ }^{21}$ For a similar approach see Caporale and Girardi (2013). We focus on manufacturing data due to greater coverage of countries. However, we have estimated the model also including trade in services and found no major changes in the results, see Section 5.4 .

${ }^{22}$ It would be possible to use international input-output tables incorporated for example in the TiVA or WIOD databases. Besides the lack of data at sufficiently disaggregated product level, issues of collinearity between $w_{i}^{i}$ and $w_{i}^{j}$ may arise.
} 


\subsubsection{Estimating the Effect of the Accounting Restructuring on Advertising Prices}

We estimate the effect of the change in Facebook's accounting practices on the (median) advertising prices in OECD countries, by means of a reducedform panel model. We account for spillovers across countries by exploiting the variation in country-level exposure to foreign advertisers from SO countries described previously. This variation is meant to explain the differences in the effect on prices across the different audiences. We postulate the following regression model:

$$
\begin{aligned}
p_{i d} & =\beta_{0}+\beta_{1} T_{d}+\beta_{2}{\widetilde{\text { Trade }_{i}}}^{\mathrm{SO}}+\beta_{3} T_{d} \times{\widetilde{\text { Trade }_{i}}}^{\mathrm{SO}}+\beta_{4} C P M_{d-1}^{U S}+\beta_{5} \ln G D P_{i q} \\
& +\mathbf{X}_{i y}^{\prime} \Gamma+\text { Hol }_{i d}+{ } W_{d}+Q_{q}+M_{m(y)}+B_{d}+\mathrm{USelec}_{d}+\varepsilon_{i d}
\end{aligned}
$$

where $T_{d}$ is a dummy equal to one for each day on and after the 7 th of March 2016. The variable $\widetilde{\operatorname{Trade}_{i}}$ SO measures the share of imports with SO countries, weighted by the relevance of products for country-i's audience, as described above:

$$
{\widetilde{\operatorname{Trade}_{i}}}_{i}=\sum_{j \in S O}{\widetilde{\operatorname{Trade}_{i j}}}_{\sum_{j}}{\widetilde{\operatorname{Trade}_{i j}}}_{\text {. }}
$$

Equation (9) also includes an interaction term between $T_{d}$ and $\widetilde{\operatorname{Trade}_{i}}{ }^{S O}$. This term accounts for the possibility that the effect of the accounting restructuring varies by country $i$, depending on the country's exposure to foreign advertisers from SO countries. Note that including $\widetilde{\text { Trade }}_{i}$ SO also takes into account exposure to foreign NS advertisers, given that ${\widetilde{\text { Trade }_{i}}}^{\text {non-SO }}=1-{\widetilde{\text { Trade }_{i}}}^{S O}$. Recall however that we do not control for exposure to domestic advertisers. Nonetheless, we estimate the model distinguishing the effects of the restructuring on $p_{i d}$ between $\mathrm{SO}$ and non-SO audiences. Given that we control for exposure to foreign advertisers, we 
can use the difference in the marginal effects of $T_{d}$ on the median price for $\mathrm{SO}$ and non-SO audiences to obtain an indication of the sign of the effect of exposure to domestic ads. We return to this point when discussing the results (Section 5.3).

We include several controls to capture the fact that differences in advertising prices across countries may depend on the size of the digital market in each country. We account for possible shocks to the digital advertising market that may have caused fluctuations in Facebook ad prices independently of changes in taxation. To this end, we include the variable $C P M_{d-1}^{U S}$, which is the weekly average CPM for a sample of internet ads in the US in the week before $d$. The US share of the global digital advertising market is by far the largest of all countries. Hence, this variable is a reasonable proxy for online ad prices 23 We also include log quarterly GDP as a measure for market size. The vector $\mathbf{X}_{i y}$ contains country-specific variables that proxy for the degree of digitization of the country's economy. This includes the penetration of e-commerce and the OECD's Services Trade Restrictiveness Index (STRI) for electronic transactions, which accounts for possible differences in regulatory restrictions on digital commerce and transactions. We provide a more detailed description of these variables in Section 5.2 .

Finally, we include a set of time controls, to account for trends and cyclicalities: $D W_{d}, Q_{q}, H o l_{i d}$ and $M_{m(y)}$ are day of the week, quarterly, holiday and monthly dummies, respectively. Furthermore, we include a dummy for the post-Brexit period $\left(B_{d}\right)$ and a dummy that equals one at the time of the US elections $\left(\mathrm{USelec}_{d}\right)$. The $\varepsilon_{i d}$ refer to idiosyncratic error terms.

To benchmark the results, we first estimate (9) to solely address the accounting policy change. For this, we first test the series for unit root

\footnotetext{
${ }^{23}$ EMarketer statistics report that the US spent 107 Billion US Dollars in digital advertising for the year 2018 alone.
} 
using the Im-Pesaran-Shin panel-data unit-root test for unbalanced panels. The results on the unit-root tests are shown in Appendix A (Table A1). We partly reject the null hypothesis of a unit root, and we clearly reject it for the demeaned series. Consequently, we use a fixed effects model as a benchmark.

Two additional issues are relevant to our data. First, autocorrelation is present in the error term, and second, daily advertising prices are autocorrelated. We thus re-estimate (9) by pooled OLS, using 8 lags of the dependent variable as chosen by the AIC, as well as by GLS ${ }^{24}$ The latter accounts for $\mathrm{AR}(1)$ autocorrelation within panels, cross-sectional correlation and heteroskedasticity across panels.

\section{$5.2 \quad$ Data}

Facebook's Ad Manager website is our main source of information ${ }^{25}$ By scraping this website, we collected the upper bound, lower bound and median of the range of ad prices (CPM) that, according to Facebook, advertisers targeting users in a given country should expect to pay. This is the range of prices advertisers pay for ads to reach that country's audience at a given time. We collected this information for each OECD country at a daily level, defining the audiences based only on country of residence (i.e., without specifying any additional characteristic). See Appendix G for more details on our data collection procedure. In the empirical analysis, we focus on the median of the range of prices for each audience, referring to them as the median prices for each audience. These prices constitute the outcome

\footnotetext{
${ }^{24}$ Dynamic models are not appropriate in this context: The time-series is long $(T>N)$ and thus the bias due to a dynamic structure becomes small. Additionally, dynamic models usually assume no autocorrelation in the errors. This autocorrelation was rejected by tests for serial correlation in the idiosyncratic errors (Wooldridge, 2002).

${ }^{25}$ The Ad Manager is the website advertisers use to acquire ads on Facebook. We briefly describe this website and the process advertisers follow to place bids on it in Appendix $\mathrm{G}$
} 
variable of our analysis 26

Summary statistics for the median prices in our panel are reported in Table 2, The median CPM is $\$ 2.57$ on average for all countries. Note that such price has increased from 0.91 before the accounting restructuring, to $\$ 3.91$ after this change. We also report the same information for the UK, which was the first country where Facebook's accounting reform was announced. The average of the median CPM before the restructuring in SO countries was $\$ 1.37$ before and about $\$ 5.34$ after the restructuring. The corresponding averages for non-SO countries are $\$ 0.52$ and $\$ 2.62$.

We also queried the Ad Manager to collect Facebook penetration rates per each audience and product category. Specifically, we collect vectors of product interests for each audience. Each vector has $k=1, . ., K$ entries, where $K$ is the number of product categories and the $k$-th entry corresponds to the share of users in country $i$ that, according to Facebook, has shown interest in a product within category $k$. We classify products using the HS 4-digit product list, to ensure categories can be mapped to products and are comparable across countries. To calculate country-specific imports from SO countries as a share of total (OECD country) imports, we combine information on product penetration rates on Facebook with information on bilateral trade between the country of the advertiser $j$ and the country of the audience $i$. Specifically, we use manufacturing imports data between 2015 and 2017 from the UN Comtrade database by goods category based on the HS classification (at the 4 digit-level), averaged across years. In order to account for the selection of products that are more likely to be advertised on Facebook in country $i$, when computing the trade shares we weigh the import volumes for each product category $k$ by the penetration

\footnotetext{
${ }^{26}$ Our results remain qualitatively unchanged when focusing on either the lower or the upper bound of the range reported by Facebook. The results also do not appear to change when focusing on other ad pricing metrics, namely CPC (Cost-Per-Click) and CPA (Cost-Per-Action).
} 
rates in country $i$, as described in section 5.1 .

Table 2 shows that, on average, a country in our sample receives about 81 percent of goods imports likely to be advertised on Facebook from SO countries (as captured by the variable ${\widetilde{\operatorname{Trade}_{i}}}_{i}$ ). This share is slightly higher for SO countries on average (84 percent), but it is substantial for non-SO ones as well (79 percent).

The weekly average CPM for online advertising in the US is obtained from Nielsen's Ad Intel dataset. The firm reports that, up to 2017, the sample of impressions in this dataset focuses on large national publishers and advertisers. Hence, it is likely that the average CPM actually overestimates the average for the universe of US ad-financed websites. Indeed, the average CPM for all digital ads (outside Facebook) in the US exceeds the CPM we observe for Facebook, at around 11 USD. In itself, the level of this variable is not important for our analysis. What matters is that there is no noticeable discontinuity in the price of ads on the US market around the announcement of Facebook's restructuring. This suggests that the restructuring did not coincide with a major change on the online advertising market in general.

Finally, to account for market size, we use the log quarterly GDP in million 2010 USD as well as yearly data on the digital STRI for electronic transactions.27 We also use data on the use of e-commerce for private individuals (Share of individuals who e-buy in percent). These data are provided by the OECD ${ }^{28}$ Table 2 shows that the average for this variable in our sample amounts to 38 percent ${ }^{29}$

\footnotetext{
${ }^{27}$ This index is computed yearly by the OECD for all member countries and provides information on regulations affecting trade in services for multiple sectors. See https: //qdd. oecd.org/subject. aspx?Subject=063bee63-475f $-427 \mathrm{c}-8 \mathrm{~b} 50-\mathrm{c} 19 \mathrm{bffa}$ 7392d ${ }^{28} \mathrm{We}$ have also collected other indicators of ICT usage by the OECD, which proved relevant in the regressions (in the sense of increasing the R-squared). As they were missing for a host of countries, in particular the US, we abstained from including them in our regressions. Note that this leads to a very slight downward bias of the coefficient for $T_{d}$.

${ }^{29}$ Appendix A (Figure A2 indicates a positive correlation between CPM prices and
} 
Table 2: Summary Statistics

\begin{tabular}{|c|c|c|c|c|c|c|c|c|c|c|c|c|}
\hline & \multicolumn{4}{|c|}{ בAll } & \multicolumn{4}{|c|}{ Before Change } & \multicolumn{4}{|c|}{ After } \\
\hline & Mean & SD & Min & Max & Mean & SD & Min & Max & Mean & $\mathrm{SD}$ & Min & Max \\
\hline \multicolumn{13}{|c|}{ A. All countries } \\
\hline Median CPM (USD) & 2.57 & 2.75 & 0.09 & 19.29 & 0.91 & 0.71 & 0.09 & 3.94 & 3.91 & 3.04 & 0.13 & 19.29 \\
\hline UK CPM (USD) & 3.74 & 2.10 & 1.19 & 8.98 & 1.72 & 0.29 & 1.19 & 3.00 & 5.37 & 1.40 & 1.43 & 8.98 \\
\hline $\mathrm{CPM}_{d-1}^{U S}$ & 10.84 & 0.23 & 10.05 & 11.23 & 10.86 & 0.19 & 10.40 & 11.16 & 10.82 & 0.25 & 10.05 & 11.23 \\
\hline${\widetilde{\text { Trade }_{i}}}^{\mathrm{SO}}$ & 0.81 & 0.10 & 0.48 & 0.97 & 0.81 & 0.10 & 0.48 & 0.97 & 0.81 & 0.10 & 0.48 & 0.97 \\
\hline Digital STRI & 0.03 & 0.01 & 0.02 & 0.04 & 0.03 & 0.01 & 0.02 & 0.04 & 0.03 & 0.01 & 0.02 & 0.04 \\
\hline $\log$ GDP & 13.03 & 1.51 & 9.56 & 16.66 & 13.02 & 1.51 & 9.59 & 16.64 & 13.04 & 1.51 & 9.59 & 16.65 \\
\hline Individuals who e-buy (\%) & 37.95 & 19.42 & 1.71 & 68.86 & & & & & & & & \\
\hline Observations & 18,900 & & & & 8.424 & & & & 10,476 & & & \\
\hline \multicolumn{13}{|c|}{ B. Sales office countries } \\
\hline Median CPM (USD) & 3.55 & 3.07 & 0.13 & 19.29 & 1.37 & 0.65 & 0.13 & 3.64 & 5.36 & 3.06 & 0.24 & 19.29 \\
\hline$\widetilde{\text { Trade }}_{i} \mathrm{SO}$ & 0.84 & 0.08 & 0.72 & 0.96 & 0.84 & 0.07 & 0.72 & 0.96 & 0.84 & 0.08 & 0.72 & 0.96 \\
\hline Observations & 8,952 & & & & 3,978 & & & & 4,947 & & & \\
\hline \multicolumn{13}{|c|}{ C. Non Sales office countries } \\
\hline Median CPM (USD) & 1.71 & 2.07 & 0.09 & 13.08 & 0.52 & 0.59 & 0.09 & 3.94 & 2.62 & 2.37 & 0.13 & 13.08 \\
\hline $\begin{array}{l}\widetilde{\text { Trade }}_{i} \text { SO } \\
\text { Observations }\end{array}$ & $\begin{array}{c}0.79 \\
9,975\end{array}$ & 0.12 & 0.48 & 0.97 & $\begin{array}{c}0.79 \\
4,446\end{array}$ & 0.12 & 0.48 & 0.97 & $\begin{array}{c}0.79 \\
5,529\end{array}$ & 0.12 & 0.48 & 0.97 \\
\hline
\end{tabular}

Notes: Sources: $C P M_{d-1}^{U S}$ (weekly average CPM from US websites), Nielsen; $\widetilde{T r a d e}_{i}$ SO (yearly final goods trade volume share with all sales office countries, 2015-2017, weighted by industry-specific penetration rates), Comtrade and own calculations; Digital STRI, electronic transactions subindex, OECD: the index lies in the unit interval, taking the value of zero in the absence of restrictions and 1 when the component is fully restrictive, and covers restrictions on electronic transactions (e.g., licenses, online tax registration, deviations from internationally accepted rules on electronic contracts, dispute settlement mechanisms); log GDP, OECD in million 2010 USD; (share of) individuals who e-buy, OECD.

\subsection{Results}

We summarize the results in Table 3. The effect of the increase in taxation in $\mathrm{SO}$ countries on the median CPM of advertising is approximately 1.1 USD on average according to the fixed effects (Column 1) and the pooled OLS model (Column 2) ${ }^{30}$ Including lags of the dependent variable ac-

trade shares with sales office countries, as well as with individuals' use of e-commerce across OECD countries.

${ }^{30}$ The fixed effects model captures potentially time-invariant factors subsumed in $\tilde{w}_{i}^{j}$ and further accounts for cyclical variations, but not for potentially simultaneous shocks. The demeaned series also clearly rejected the null hypothesis of a unit root. 
counts for autocorrelation in advertising prices and reduces the coefficient of interest significantly to 0.136 , indicating a substantial upward bias in the previous results. Taking into account serial correlation in the idiosyncratic errors and and cross-sectional dependence by way of a GLS model (Column 4) results in a coefficient of 0.277. Note that including lags of the dependent variable may lead to substantial bias in the presence of serial correlation, and thus the true effect may lie somewhere between those found in Columns 3 and 431

Next, we account for import shares from SO countries, which we include in Columns 5 to 7 . These suggest that the effect of the increase in taxation on the median price of advertising to a country not exposed to foreign SO advertisers is negative on average and very small. However, higher exposure to such advertisers has a positive and mostly significant effect on the price following the break. Thus, each additional unit of exposure to foreign SO advertisers (captured by interest-weighted import shares) strengthens the effect of taxation on the median price of advertising, which is in line with our conjecture that prices depend on the exposure of audiences to foreign advertisers, whereby the exposure is proxied by import demand. Given the substantial share of SO countries imports - roughly 80 percent on average (see Table 2) - the marginal effect of the increase in taxation evaluated at the average level of exposure to foreign SO advertisers is also positive; it ranges from 0.136-0.293, according our models (the POLS model estimated with LDV and the model estimated by GLS). The overall effects are thus unchanged compared to the results shown in Columns 2 to 432

To shed more light on the role of an audience's exposure to SO and nonSO ads for the effect of taxation on the median price, we break down the

\footnotetext{
${ }^{31}$ This argument may be further supported by the observation that the lagged variables amount to about 1 and the $R^{2}$ approaches 1 as well.

${ }^{32} \mathrm{We}$ also used services import shares from the OECD instead of goods import shares. Using this formulation, the total (POLS) effects amount to 1.118 (standard error 0.079).
} 
previous estimates distinguishing between audiences located in SO versus non-SO countries in Columns 8 and 9 of Table 3 . We exclude the US as an observation in both groups because Facebook's US revenue was taxed at the local rate before and after the accounting change. Note that this does not affect the exposure to sales-office countries as measured by $\widetilde{\text { Trade }_{i}}$ SO because the local selling structure applies to the aggregate of these countries.

To interpret the differential effect the accounting restructuring had across SO and non-SO countries, we look at what happens at the average exposure to incoming trade from SO countries (bottom row, Columns 8 and 9). The effect on the median price of ads is positive and significant for both SO and non-SO audiences. However, the size of this effect is substantially larger in the former $(\$ 0.455)$ than in the latter $(\$ 0.137)$. That is, given the average exposure to foreign SO (and non-SO) advertisers, and conditional on other controls, the effect of taxation on the median price of ads is larger for audiences in SO countries. Recall, however, that we do not control for exposure to domestic advertisers directly. Therefore, this finding suggests that exposure of non-SO audiences to domestic advertisers is likely to decrease the median price of ads to such audiences, whereas exposure to foreign SO ads tends to increase the price. In all, the results appear to be consistent with the predictions of our theoretical model, which shows that, after the increase in tax rates in $\mathrm{SO}$ countries, the prices paid by advertisers from $\mathrm{SO}$ countries should increase, unlike the prices paid by advertisers from non-SO countries.

As a robustness check, we report findings akin to ones reported in Table 3. for a sample that we have trimmed before June 2016 instead of for all data up to February 2017 in Table A3. The reason is that several breaks have occurred in the data after that date. For example, the scraping algorithm has paused on two occasions after that date and prices have decreased after 
July 2016 but settled on an overall higher level than before 7 March 2016 (see Figure 2). The results remain qualitatively robust at large and are quantitatively just slightly below the ones presented in Table 3 .

Table 3: EFFECT of FACEBOOK ACCOUNTING RESTRUCTURING ON ONLINE AD PRICES

\begin{tabular}{|c|c|c|c|c|c|c|c|c|c|}
\hline & $\begin{array}{l}1) \\
\mathrm{FE}\end{array}$ & $\begin{array}{c}(2) \\
\text { POLS }\end{array}$ & $\begin{array}{c}(3) \\
\text { POLS }\end{array}$ & $\begin{array}{c}(4) \\
\text { GLS }\end{array}$ & $\begin{array}{c}(5) \\
\text { POLS }\end{array}$ & $\begin{array}{c}(6) \\
\text { POLS }\end{array}$ & $\begin{array}{c}(7) \\
\text { GLS }\end{array}$ & $\begin{array}{c}(8) \\
\text { non-SO }\end{array}$ & $\begin{array}{l}(9) \\
\text { SO }\end{array}$ \\
\hline$T_{d}$ & $\begin{array}{c}1.137 \\
(0.140)\end{array}$ & $\begin{array}{c}1.116 \\
(0.137)\end{array}$ & $\begin{array}{c}0.136 \\
(0.016)\end{array}$ & $\begin{array}{c}0.277 \\
(0.026)\end{array}$ & $\begin{array}{c}-2.715 \\
(0.175)\end{array}$ & $\begin{array}{c}0.092 \\
(0.029)\end{array}$ & $\begin{array}{c}-0.074 \\
(0.193)\end{array}$ & $\begin{array}{c}0.233 \\
(0.185)\end{array}$ & $\begin{array}{c}-2.575 \\
(0.555)\end{array}$ \\
\hline${\text { Trade }_{i}}$ & & & & & $\begin{array}{l}-2.495 \\
(0.126)\end{array}$ & $\begin{array}{c}-0.032 \\
(0.020)\end{array}$ & $\begin{array}{c}1.377 \\
(0.489)\end{array}$ & $\begin{array}{l}-1.729 \\
(0.545)\end{array}$ & $\begin{array}{c}2.039 \\
(1.163)\end{array}$ \\
\hline$T_{d} \times{\widetilde{\operatorname{Trade}_{i}}}_{i}$ & & & & & $\begin{array}{c}4.762 \\
(0.191)\end{array}$ & $\begin{array}{c}0.055 \\
(0.034)\end{array}$ & $\begin{array}{c}0.456 \\
(0.244)\end{array}$ & $\begin{array}{c}-0.059 \\
(0.235)\end{array}$ & $\begin{array}{c}3.879 \\
(0.673)\end{array}$ \\
\hline $\begin{array}{l}\text { Obs. } \\
\mathrm{R}^{2}\end{array}$ & $\begin{array}{c}18,900 \\
0.657\end{array}$ & $\begin{array}{c}18,900 \\
0.666\end{array}$ & $\begin{array}{c}18,612 \\
0.992\end{array}$ & 18,900 & $\begin{array}{c}18,900 \\
0.672\end{array}$ & $\begin{array}{c}18,612 \\
0.992\end{array}$ & 18,900 & 9,975 & 8,925 \\
\hline Effect at $\operatorname{Avg}($ & $\operatorname{rade}_{i}$ ) & & & & $\begin{array}{c}1.115 \\
(0.080)\end{array}$ & $\begin{array}{c}0.136 \\
(0.015)\end{array}$ & $\begin{array}{c}0.293 \\
(0.027)\end{array}$ & $\begin{array}{c}0.137 \\
(0.027)\end{array}$ & $\begin{array}{c}0.455 \\
(0.056)\end{array}$ \\
\hline
\end{tabular}

Notes: Model [1] is estimated using a fixed effects panel model, models [2] and [3] by pooled OLS - where model [3] includes 8 lags of the dependent variable in addition (as suggested by the AIC) - and model [4] by GLS. Models [5]-[7] include goods imports from countries with a sales office, weighted by country specific product interests, whereby [5] is estimated by POLS, [6] includes 8 lags of the dependent variable, and [7] is estimated by GLS. [8] and [9] are estimated by GLS for non-SO and SO countries, respectively. All models control for the average weekly CPM of the US national internet market (not reported) and further include day-of-the-week dummies, quarterly dummies, holiday dummies, month-year dummies, a dummy for brexit, a dummy for the US elections. Models in [2]-[9] also include the digital STRI, quarterly log GDP, and ICT usage (all OECD). Standard errors clustered at the country level in parentheses.

\subsection{Spatial Price Interdependence}

To test the robustness of our results, we account for the interdependence of prices, or more precisely, for the role of price spillovers across countries, by a spatial estimation approach. This allows for a more complex structure for the network between an audience and the different countries where all advertisers targeting that audience are located. It also acknowledges the potential concern that supply and demand-side forces cannot be separately identified, representing a more flexible approach than the one described 
in 5.1.1. The latter could include for instance anticipation effects of tax reforms in other countries than the UK, which have not been explicitly accounted for in the previous section. We build an $n \times n$ spatial weighting matrix $\mathbf{W}$ with elements $w_{i j}$ capturing the strength of the relationship between the audience of country $i$ and the advertisers from country $j$.

Consistent with the previous section, we construct a weighting matrix based on $\widetilde{\operatorname{Trade}}_{i j}$, trade of $i$ and $j$, weighted by the interests of $i$ 's audience in the products traded with $j$ (corresponding to eq. (7)). Thereby we focus on total trade (the sum of exports and imports) to capture patterns of interdependence through trade between countries in a more appropriate way than when using imports only. Since we now exploit a bilateral structure for $w_{i j}$, we propose different alternative matrices that account for patterns of trade between countries. Note that the matrix has a zero diagonal but has non-zero trade in the off-diagonal elements of the matrix, and is min-max normalized $\sqrt[33]{3}$ Alternative spatial weighting matrices are based on geographical distance between countries (inspired by the gravity model of trade and taking into account explicitly the relevance of trade costs), and the number of flight connections between countries as a second weighting matrix taking into account the social network between countries ${ }^{34}$

\footnotetext{
${ }^{33}$ Note that we also set trade with non-SO countries to zero.

${ }^{34}$ For related approaches see e.g., Behrens et al. (2012); Lee and Pace (2005); LeSage and Pace (2008). The use of distance is common in the trade literature to proxy for trade costs. The limitations of the distance matrix is that it may not be appropriate for proxying a network of online advertising, because this often pertains services that are distributed at nearly zero trade cost. Our last approach moves on to collecting data on the number of flights between the countries in our sample. The source is https://openflights.org/. For each airport, this database collects all connections from that airport to other airports by country. This spatial weighting matrix based on flight connections represent an alternative way of capturing the cultural vicinity among countries, something that is particularly relevant for the distribution of advertising. We also tested bilateral trade predicted from a gravity equation estimated by PPML, with $i j$-imports from the UN Comtrade database as the dependent variable, and log distance, contiguity, common official language, colonial history (all from CEPII), as well as importer and exporter fixed effects as independent variables, with similar results.
} 
We formulate the spatial model as follows:

$$
\begin{aligned}
p_{i d} & =\gamma_{0}+\gamma_{1} p_{i d-1}+\rho \sum_{j=1}^{n} w_{i j} p_{j d}+\gamma_{2} T_{d}+\gamma_{3} C P M_{d-1}^{U S}+\gamma_{4} S T R I_{i y} \\
& +\gamma_{5} \ln G D P_{i q}+H o l_{i d}+D W_{d}+Q_{i q}+M_{m(y)}+B_{d}+\mathrm{USelec}_{d}+\nu_{i d}
\end{aligned}
$$

where $\nu_{i d}=\lambda \sum_{j=1}^{n} w_{i j} v_{j d}+u_{i d}$. The equation is estimated by maximum likelihood using different spatial panel models. We rely on fixed effects spatial autoregressive (SAR) models, assuming that $\lambda=0$, as well as an autoregressive model with autoregressive disturbances (SAC). Adding $p_{i d-1}$ to eq. 11 allows for a dynamic structure, yet we additionally estimate models excluding the lagged dependent variable.

Two results stand out 35 First, we find that the estimates on both $\rho$ and $\lambda$ are mostly significant, indicating that the concern of spatial interdependence is valid ${ }^{36}$ Second, the main effects on the break are quantitatively and qualitatively similar to the ones shown in Table 3. Also in line with previous findings, using a dynamic model substantially changes these results (Columns 1 and 4), as the inclusion of a lag of the dependent variable decreases the coefficients to about 0.1 at best when using a dynamic model.

Additionally, direct, indirect and total effects are reported. The direct effect indicates the effect of the accounting restructuring in country $i$ on prices in country $i$, averaged over all countries, and the total effect can be interpreted as the effect of the policy change in $i$ on prices in all countries, averaged over all countries. The indirect effect is the difference between

\footnotetext{
${ }^{35}$ Table $\mathrm{A} 2$ in Appendix $\mathrm{A}$ summarizes the results from the estimation of eq. (11). The table is organized such that the main effect is displayed in panel A. Since the accounting restructuring for the UK, interpreting this coefficient is straightforward.

${ }^{36}$ Since $\rho, \lambda \neq 0$, either a spatial autoregressive model (SAR) or a spatial autoregressive model with autoregressive disturbances (SAC) is preferred compared to the spatial Durbin (SDM) - which assumes that $\lambda=0$ - or the spatial error model (SEM), which assumes that $\rho=0$.
} 
the two (total minus direct). The estimates of the indirect effect are positive and statistically significant when using our preferred version of $\mathbf{W}$, indicating that there is feedback from neighbours' prices. What we would be interested in is thus the total effect, which amounts to about 1.1 when we exclude the lagged dependent variable, and to 0.1 when we include the lagged dependent variable.

\subsection{Implied Tax Pass-through rates}

To put our estimates in perspective, we evaluate the pass-through rate of profit taxes on advertising prices implied by our estimates. Estimates indicate that the median price to reach audiences in OECD countries rose on average by $\$ 0.29$ due to the increase in taxes Facebook pays in SO countries (Table 3, Column 7). However, the lower bound of our estimates (Table A2, column 4) shows an effect of $\$ 0.09$. Given an average CPM in the period before the tax change of $\$ 0.91$, the price thus increased by about 10 to 32 percent. The average price increase for the subset of audiences located in SO countries is about 35 percent and 26 percent in non-SO countries (based on the estimates in Table 3 , Columns 8 and 9)

The average statutory corporate tax rate in OECD countries where Facebook has a sales office is 25.9 percent ${ }^{38}$ Because Facebook's advertising revenue was booked in Ireland before the tax change, the initial corporate tax rate of reference is the Irish one, equal to 12.5 percent. However, it is conceivable that the effective tax rate paid by Facebook in Ireland is substantially lower. Assuming an unchanged effective OECD average tax rate, we consider 12.5 percent as the upper bound of the initial tax rate

\footnotetext{
${ }^{37}$ Given estimates based on pooled models which do not include a lagged dependent variable (amounting to \$1.1), the price increase even amounts to up to 150 percent. However, our preferred estimates are from models including lagged dependent variables or control for serial correlation, and we concentrate on those estimates here.

${ }^{38}$ This is the average of the combined tax rate reported in the OECD Stats Database (Table II.1). See https://stats.oecd.org/index.aspx?DataSetCode=Table_II1.
} 
and zero percent as the lower bound. The lower bound on the average tax increase in SO countries is thus 13.4 percent, and the upper bound is 25.9 percent. Table 4 reports the profit tax pass-through on the median advertising prices for OECD audiences on average. We also report the results distinguishing between audiences in $\mathrm{SO}$ and non-SO countries ${ }^{39}$

The results of this exercise are quite sensitive to the model specification as well as the effective Irish tax rate. Given our preferred (GLS) estimates, the effect on ad prices (\$0.29) suggests overshifting of taxes on ad prices (pass-through rate between 1.23 and 2.68). However, the lower bound of our estimates would suggest undershifting (pass-though rate between 0.38 and 0.83$)$

In the last two columns of Table 4 we distinguish the effect between prices for audiences in sales-office (SO) and non-sales-office (non-SO) countries (based on the estimates from Table 3, columns 8 and 9). Notably, passthrough tends to be higher in non-sales-office countries, primarily because the initial CPM for audiences in such countries tends to be substantially smaller than for sales-office countries (we report disaggregate results by country in Appendix D.

\footnotetext{
${ }^{39}$ We use the following formula for pass-through: $\frac{\Delta p}{p} / \frac{\Delta t}{1+t}$, where $\Delta p$ is the estimated increase in the average CPM (\$0.09 and $\$ 0.29$ overall, $\$ 0.45$ for sales-office and $\$ 0.14$ for non-SO), $p$ is the average CPM in the period up to March 2016 (\$0.91 overall, $\$ 1.37$ for $\mathrm{SO}$ and $\$ 0.52$ for non-SO), $t$ is the Irish tax rate (assumed between 12.5 percent and zero) and $\Delta t$ is the difference between the average corporate tax rate in OECD countries where Facebook has a sales office (25.9 percent) and $t$.

${ }^{40}$ The literature shows that overshifting of commodity taxes on goods prices can occur in imperfectly competitive markets -even with a monopolist supplier (Weyl and Fabinger, 2013)- as well as competitive ones (Agrawal and Hoyt, 2019.
} 
Table 4: Average PASs-Through in OeCD COUNTRIES, SALES-OFFICE AND NON SALES-OFFICE COUNTRIES

\begin{tabular}{ccccc}
\hline \hline & \multicolumn{4}{c}{ Pass-through } \\
Tax rate IRL & ALL (0.09) & ALL (0.29) & SO & non-SO \\
\cline { 2 - 4 } $12.50 \%$ & 0.83 & 2.68 & 2.21 & 3.16 \\
$6.25 \%$ & 0.53 & 1.72 & 1.42 & 2.03 \\
$0 \%$ & 0.38 & 1.23 & 1.02 & 1.45 \\
\hline \hline
\end{tabular}

Notes: We compute the pass-through in each country using the upper and lower bound of the estimated effect on CPM (see Tables 3 and A2 and considering as the pre-reform tax rate the tax rate in Ireland (IRL), allowed to range between 12.5 and 0 percent. The post-reform tax rate is the average tax rate in Sales-Office countries, 25.9 percent.

To our knowledge, there are no previous estimates of tax pass-through rates on digital advertising prices. However, we can compare our results to existing estimates of VAT pass-through on the prices of consumer goods and services. The VAT literature typically estimates pass-through rates from 0.2 to 1.6 (Benedek et al., 2015). Given the highly plausible scenario that Facebook pays a tax rate close to zero in Ireland, our preferred estimates of pass through are at the high end of this spectrum. However, given the (less plausible, in our view) assumption that Facebook pays the full statutory tax rate in Ireland, our estimates suggest that pass-through is greater than previous estimates for VAT.

There are many differences between markets for consumer goods and services and the market we consider. For instance, the former are typically not dominated by two-sided platforms, unlike the market for advertising on social media. Given these differences, one should take the comparison of pass-through rates between the markets for social media ads and consumer goods with some caution. 


\section{Welfare Analysis}

We provide a basic evaluation of the effects on welfare of the tax changes considered above by comparing welfare before and after the tax increase. These scenarios are referred to as pre-tax and post-tax scenario in the following. The analysis is based on the theoretical model of Section 4.3 , that we extent to account for six countries. Furthermore, we specify consumer utility and advertiser profits in order to compute the respective surpluses. We calibrate the model using data from the following countries: Germany, France, UK, Japan, Mexico and the US. The first four are SO countries where Facebook revenue was taxed at the local rate only after the restructuring. The US is an SO country, but the ad revenue therein was booked locally before the accounting change. Finally, Mexico is a non-SO country. We focus on a restricted number of six countries for computational reasons. For reasons of space, we relegate the description of the model, data and calibration to Appendix E.

In the initial (pre-tax) scenario, we assume the platform does not pay any tax, except in the US. As for the post-tax scenario, we assume the platform pays no taxes in Mexico, which is a NS country, and pays the statutory corporate tax rate in Germany, France, UK, Japan and the US (SO countries). Details about the data used, results for the quantity of ad impressions to users as well as the prices of ads in the two scenarios are depicted in Appendix $\mathrm{E}{ }^{41}$

Table 5 summarizes the effects of the tax change on welfare, distinguishing between consumers, advertisers, the platform and the government. We find relatively small effects on total welfare, which decreases slightly, by 1 to 2 percent in the countries where the tax rate increased. By contrast, total welfare rises in Mexico and the US. However, the model suggests that

\footnotetext{
${ }^{41}$ Note that a homogenization of taxes in all countries would be another interesting counterfactual.
} 
taxation has relevant distributional effects. Specifically, there is a substantial decrease of about 10 percent on average in advertiser surplus in the countries where the tax rate went up, due to the increase in ad prices. On the other hand, advertisers from Mexico and the US are better off because ads are cheaper for them. Furthermore, we find an increase in consumer surplus in all countries, due to the overall reduction in the exposure to ads due to the increase in taxation. However, given the rather small reduction in the total provision of ads, the effect on consumer surplus is small. Finally, a significant share of the platform's profits are taxed away in SO countries.

Table 5: WELFARE CHANGES

\begin{tabular}{|c|c|c|c|c|c|c|}
\hline \multicolumn{7}{|c|}{ Pre-Tax Scenario } \\
\hline & GER & FRA & UK & JPN & MEX & USA \\
\hline Daily users ('000) & 20,884 & 22,215 & 29,062 & 13,715 & 44,559 & 177,009 \\
\hline Advertiser Surplus ( $\$ \mathrm{M})$ & 5,341 & 1,579 & 9,628 & 7,124 & 731 & 12,072 \\
\hline Consumer Surplus (\$M) & 11,331 & 11,497 & 16,482 & 7,007 & 19,356 & 78,521 \\
\hline Tax Revenue $(\$ M)$ & 0 & 0 & 0 & 0 & 0 & 25,002 \\
\hline Platform Profit ( $\$ \mathrm{M})$ & 8,017 & 3,407 & 13,450 & 8,903 & 1,724 & 43,511 \\
\hline Welfare $(\$ M)$ & 24,689 & 16,483 & 39,560 & 23,034 & 21,811 & 159,107 \\
\hline \multicolumn{7}{|c|}{ Post-Tax Scenario } \\
\hline & GER & FRA & UK & JPN & MEX & USA \\
\hline Daily users ('000) & 20,921 & 22,273 & 29,077 & 13,881 & 44,964 & 177,156 \\
\hline Advertiser Surplus $(\$ M)$ & 4,921 & 1,289 & 8,956 & 6,602 & 836 & 12,467 \\
\hline Consumer Surplus (\$M) & 11,363 & 11,546 & 16,495 & 7,130 & 19,659 & 78,651 \\
\hline Tax Revenue (\$M) & 2,355 & 1,131 & 2,564 & 2,614 & 0 & 23,945 \\
\hline Platform Profit ( $\$ \mathrm{M})$ & 5,766 & 2,196 & 10,929 & 6,399 & 1,754 & 44,348 \\
\hline Welfare $(\$ M)$ & 24,405 & 16,162 & 38,944 & 22,745 & 22,248 & 159,411 \\
\hline
\end{tabular}

\section{Conclusion}

We have provided a first exploration of the effects of taxation on MDPs. We show novel evidence on the incidence of taxation of digital platforms on the 
online advertising market. We study the effect of a change in Facebook's accounting practices that took place in March 2016. We show that advertising prices increase substantially not only in the countries where taxation on the platform's revenue increased, but also in other countries. We find generally starker effects for countries that exhibit larger market shares of advertisers based in countries where taxation increased. Our findings are consistent with a theoretical model of a two-sided platform operating in the global advertising market.

These results highlight the relevance of international spillovers among advertising prices, in a market dominated by a large multinational digital platform. In particular, we show that these spillovers relate to pre-existing international trade patterns. This implies that unilateral corporate taxes on digital platforms may influence the price and distribution of ads across countries, even absent tax reform in the countries themselves. Therefore, the effects of taxes may extend beyond the allocation of accounting profits (e.g., through transfer pricing) in ways that signal a departure from the dynamics associated with traditional multinational enterprises.

The analysis has relevant implications for the design of taxes on digital platforms, and aims to address the current debate on proposed reforms to international corporate tax systems. Our results suggest that policymakers should carefully evaluate the potential consequences of taxes on digital platforms on i) the level and distribution of ads and prices across different audiences and ii) the price spillovers due to the global advertising network. In the context of ad hoc tax systems for the digital economy, our paper moves toward the idea of attributing shares of created values to the locations of users who are the targets of online advertising. 


\section{Bibliography}

Agrawal, David Robert and Hoyt, William H., "Pass-Through in a Multiproduct World". 2019. Available at SSRN: https://ssrn.com/abstract=3173180

Ambrus, Attila, Emilio Calvano and Markus Reisinger. 2016. "Either or Both Competition: A 'Two-Sided' Theory of Advertising with Overlapping Viewerships." American Economic Journal: Microeconomics 8(3): 189-222, http://dx.doi.org/10.1257/mic.20150019.

Anderson, Simon P. and Stephen Coate. 2005. "Market Provision of Broadcasting: A Welfare Analysis." Review of Economic Studies 72(4): 947-972, https://doi.org/10.1111/0034-6527.00357.

Argentesi, Elena and Lapo Filistrucchi. 2007. "Estimating Market Power in a Two Sided Market: The Case of Newspapers." Journal of Applied Econometrics 22(7): 1247-1266, https://doi.org/10.1002/jae. 997.

Auerbach, Alan J. and Yuriy Gorodnichenko. 2013. "Output Spillovers from Fiscal Policy." American Economic Review: Papers and Proceedings 103(3): 141-146, http://dx.doi.org/10.1257/aer.103.3.141.

Bedre-Defolie, Özlem and Emilio Calvano. 2013. "Pricing Payment Cards." American Economic Journal: Microeconomics 5(3): 206-231, http://dx.doi.org/10.1257/mic.5.3.206.

Beetsma, Roel, Massimo Giuliodori, Franc Klaassen and Volker Wieland. 2006. "Trade Spill-Overs of Fiscal Policy in the European Union: A Panel Analysis." Economic Policy 21(48): 640-687, https://doi.org/10.1111/ j.1468-0327.2006.00168.x

Behrens, Kristian, Cem Ertur and Wilfried Koch. 2012. "'Dual' Gravity: Using Spatial Econometrics to Control for Multilateral Resistance." Journal of Applied Econometrics 27(5): 773-794, https://doi.org/10. 1002/jae.1231.

Belleflamme, Paul and Eric Toulemonde. 2018. "Tax Incidence on 
Competing Two-Sided Platforms: Lucky Break or Double Jeopardy." Journal of Public Economic Theory 20(1): 9-21, https://doi.org/10.1111/ jpet. 12275 .

Benedek, Dora, Ruud De Mooij and Philippe Wingender. 2015. "Estimating VAT Pass Through." IMF Fiscal Affairs Department Working Paper 15/214.

Bibler Andrew J., Keith F. Teltser and Marc J. Tremblay. 2018. "Inferring Tax Compliance from Pass-through: Evidence from Airbnb Tax Enforcement Agreements." Working Paper, McMaster University.

Bloch, Francis and Gabrielle Demange. 2018. "Taxation and Privacy Protection on Internet Platforms." Journal of Public Economic Theory 20(1): 52-66, https://doi.org/10.1111/jpet.12243.

Boik, Andre. 2016. "Intermediaries in Two-Sided Markets: An Empirical Analysis of the US Cable Television Industry." American Economic Journal: Microeconomics 8(1): 256-282, http://dx.doi.org/10.1257/ mic.20140167,

Bourreau, Marc, Bernard Caillaud and Romain De Nijs. 2018. "Taxation of a Monopolist Digital Platform." Journal of Public Economic Theory 20(1): 40-51, https://doi.org/10.1111/jpet.12255.

Cabañas, José G., Ángel Cuevas and Rubén Cuevas. 2017. "FDVT: Data Valuation Tool for Facebook Users." ACM Conference on Human Factors in Computing Systems (CHI '17).

Caporale, Guglielmo M. and Alessandro Girardi. 2013. "Fiscal Spillovers in the Euro Area." Journal of International Money and Finance 38: 84.e184.e16, https://doi.org/10.1016/j.jimonfin.2013.05.002.

Cavallo, Alberto F. 2017. "Are Online and Offline Prices Similar? Evidence from Large Multi-channel Retailers." American Economic Review 107(1): 283-303, https://doi.org/10.1257/aer.20160542.

Devereux, Michael P., Ben Lockwood and Michaela Redoano. 2008. 
"Do Countries Compete Over Corporate Tax Rates?" Journal of Public Economics 92(5-6): 1210-1235, https://doi.org/10.1016/j.jpubeco. 2007.09 .005 .

Economides, Nicholas and Benjamin E. Hermalin. 2012. "The Economics of Net Neutrality." RAND Journal of Economics 43(4): 602-629, , http://dx.doi.org/10.2139/ssrn.1723945.

EU. 2016. "Tax Challenges in the Digital Economy." European Parliament Think Tank. http://www.europarl.europa.eu/thinktank/en/ document.html?reference=IPOL_STU\%282016\%29579002, last consulted on 17 January 2019.

Fajgelbaum, Pablo D. and Amit K. Khandelwal. 2016. Measuring the Unequal Gains from Trade. The Quarterly Journal of Economics: 131(3): 1113â1180, https://doi.org/10.1093/qje/qjw013.

Frenkel, Jacob, Assaf Razin and Steve Symansky. 1990. "International Spillovers of Taxation." Chapter in in Assaf Razin and Joel Slemrod, editors. Taxation in the Global Economy. National Bureau of Economic Research, University of Chicago Press: 211-262.

Goujard, Antoine 2017. "Cross-Country Spillovers from Fiscal Consolidations. Fiscal Studies 38(2): 219-267.

Kind, Hans J., Marko Koethenbuerger and Guttorm Schjelderup. 2008. "Efficiency-Enhancing Taxation in Two-Sided Markets." Journal of Public Economics 92(5-6): 1531-1539, https://doi.org/10.1016/j.jpubeco. 2007.12.010.

Kind, Hans J. and Jarle Moen. 2015. "Effects of Taxes and Subsidies on Media Services." In R.G. Picard and S.S. Wildman, eds. Handbook on the economics of the media. Edgar Elgar, https://doi.org/10.4337/ 9780857938893 .

Kotsogiannis, Christos and Konstantinos Serfes. 2010. "Public Goods and Tax Competition in a Two-Sided Market." Journal of Public Economic 
Theory 12(2): 281â321, https://doi.org/10.1111/j.1467-9779.2009. $01439 \cdot \mathrm{x}$.

Jeziorski, Przemyslaw. 2014. "Effects of Mergers in Two-Sided Markets: The US Radio Industry." American Economic Journal: Microeconomics, 6(4): 35-73, http://dx.doi.org/10.1257/mic.6.4.35.

Lee, Ming-Long and R. Kelley Pace. 2005. "Spatial Distribution of Retail Sales." The Journal of Real Estate Finance and Economics, 31(1): 53-69, https://doi.org/10.1007/s11146-005-0993-5.

Lendle, Andrea, Marcelo Olarreaga, Simon Schropp and Pierre-Louis Vézina. 2016. "There Goes Gravity: eBay and the Death of Distance." Economic Journal, 126(591): 406-441, https://doi.org/10.1111/ecoj. 12286.

LeSage, James P. and R. Kelley Pace. 2008. "Spatial Econometric Modeling of Origin-Destination Flows." Journal of Regional Science 48(5): 941-967, https://doi.org/10.1111/j.1467-9787.2008.00573.x.

Linder, Staffan B. 1961. "An Essay on Trade and Transformation." Stockholm: Almqvist \& Wicksell.

OECD. 2015. "Addressing the Tax Challenges of the Digital Economy, Action 1 - 2015 Final Report." OECD Publishing, Paris, https://dx. doi.org/10.1787/9789264241046-en.

OECD. 2018. "Tax Challenges Arising from Digitalisation - Interim Report 2018: Inclusive Framework on BEPS, OECD/G20 Base Erosion and Profit Shifting Project." OECD Publishing, Paris, https://doi.org/ 10.1787/9789264293083-en

Rochet, Jean-Charles and Jean Tirole. 2003. "Platform Competition in Two-Sided Markets." Journal of the European Economic Association 1(4): 990-1029.

Rochet, Jean-Charles and Jean Tirole. 2006. "Two-sided Markets: a Progress Report." RAND Journal of Economics 37(3): 645-667. 
Romer, Christina D. and David H. Romer. 1989. "Does Monetary Policy Matter? A New Test in the Spirit of Friedman and Schwartz." NBER Chapters, in: NBER Macroeconomics Annual 1989(4): 121-184 National Bureau of Economic Research, Inc, https://doi.org/10.1086/ 654103.

Weyl, E. Glen and Michal Fabinger. 2013. "Pass Through as an Economic Tool: Principles of Incidence under Imperfect Competition." Journal of Political Economy 121(3): 528-583, https://doi.org/10.1086/ 670401.

Wilbur, Kenneth C. 2008. "A Two-Sided, Empirical Model of Television Advertising and Viewing Markets." Marketing Science 27(3): 356-378, https://doi.org/10.1287/mksc.1070.0303.

Wooldridge, Jeffrey M. 2002. "Econometric Analysis of Cross Section and Panel Data." Cambridge, MA: MIT Press. 


\section{Appendix for online publication}

\section{A Supplementary Figures and Tables}

Figure A1: Online ADVERTISING MARKET SHARE OF DOMINANT PLATFORMS

\section{Net Digital Ad Revenue Shares - Worldwide}

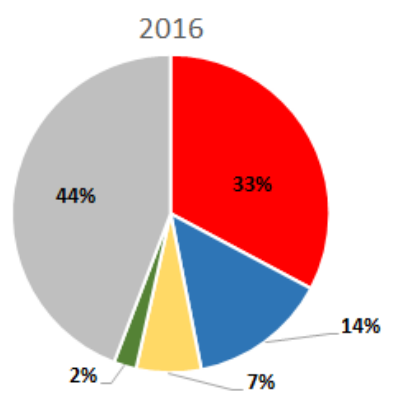

Total $=190 \mathrm{bln}$ USD

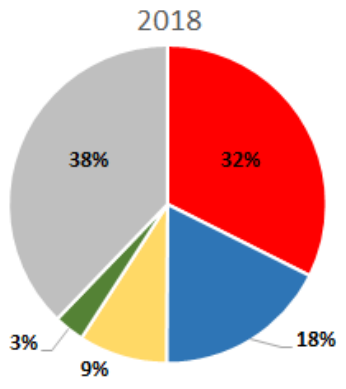

Total $=258 \mathrm{bln}$ USD

- Google - Facebook $\approx$ Alibaba " Microsoft $=$ Others

Source: Statista, 2019

Figure A2: Cpm PRICES, TRADE SHARES With SO COUNTRIES, AND ICT USAGE
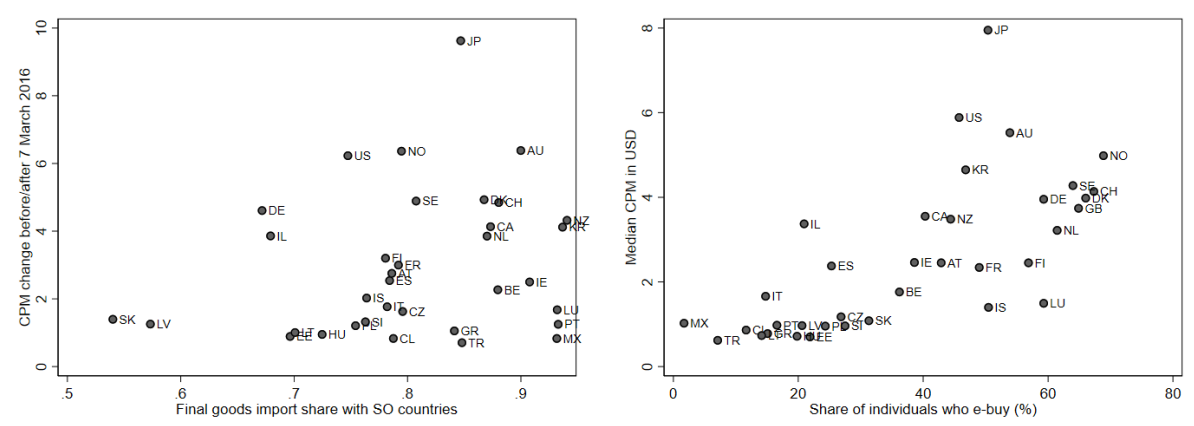

Note: $\widetilde{\text { Trade }}_{i}^{S O}$ is yearly final goods import volume share with all sales office countries, 2015-2017, weighted by industry-specific penetration rates); (share of) individuals who e-buyOECD countries only. Source: Comtrade and own calculations; OECD. 
Table A1: Test FOR Unit ROOT OF MEDIAN CPM

\begin{tabular}{lrrr}
\hline \hline & $(1)$ & $(2)$ & $(3)$ \\
Statistic & DF & IPS & IPS \\
\hline $\mathrm{Z}(\mathrm{t})$ & -1.873 & -3.738 & -11.5353 \\
$\mathrm{p}$-value & 0.345 & 0.0001 & 0.000 \\
\hline \hline
\end{tabular}

Column (1) uses the augmented Dickey-Fuller test for the UK only. Columns (2) and (3) are based on the ImPesaran-Shin (2003) test for unbalanced panels. Z(t) denotes the test statistic. The null hypothesis is that all the panels contain a unit root. Column (3) subtracts crosssectional means. 
Table A2: EFFECT OF FACEBOOK ACCOUNTING RESTRUCTURING ON ONLINE AD PRICES FOR SPATIAL MODELS

\begin{tabular}{|c|c|c|c|c|c|c|c|c|c|}
\hline & $\begin{array}{c}(1) \\
\text { SAR }\end{array}$ & $\begin{array}{c}\text { SAR }_{\text {Trade }_{i j}} \\
\text { S }\end{array}$ & $\begin{array}{c}(3) \\
\text { SAC }\end{array}$ & $\begin{array}{c}(4) \\
\text { SAR }\end{array}$ & $\begin{array}{c}(5) \\
\text { SAR } \\
\text { Distance }\end{array}$ & $\begin{array}{c}(6) \\
\text { SAC }\end{array}$ & $\begin{array}{c}(7) \\
\text { SAR }\end{array}$ & $\begin{array}{c}(8) \\
\text { SAR } \\
\text { No. flights }\end{array}$ & $\begin{array}{c}(9) \\
\text { SAC }\end{array}$ \\
\hline \multicolumn{10}{|c|}{ A. Main effect } \\
\hline $\begin{array}{l}T_{d} \\
p_{i d-1}\end{array}$ & $\begin{array}{c}0.110 \\
(0.013) \\
0.969 \\
(0.006) \\
\end{array}$ & $\begin{array}{c}0.897 \\
(0.140)\end{array}$ & $\begin{array}{c}0.922 \\
(0.148)\end{array}$ & $\begin{array}{c}0.087 \\
(0.014) \\
0.970 \\
(0.006) \\
\end{array}$ & $\begin{array}{c}0.674 \\
(0.214)\end{array}$ & $\begin{array}{c}0.632 \\
(0.276)\end{array}$ & $\begin{array}{c}0.108 \\
(0.013) \\
0.974 \\
(0.005) \\
\end{array}$ & $\begin{array}{c}0.995 \\
(0.164)\end{array}$ & $\begin{array}{c}0.990 \\
(0.164)\end{array}$ \\
\hline \multicolumn{10}{|c|}{ B. Direct effect } \\
\hline$T_{d}$ & $\begin{array}{c}0.108 \\
(0.014) \\
\end{array}$ & $\begin{array}{c}0.907 \\
(0.140) \\
\end{array}$ & $\begin{array}{c}0.937 \\
(0.147) \\
\end{array}$ & $\begin{array}{c}0.085 \\
(0.014) \\
\end{array}$ & $\begin{array}{c}0.678 \\
(0.204) \\
\end{array}$ & $\begin{array}{c}0.641 \\
(0.259) \\
\end{array}$ & $\begin{array}{c}0.106 \\
(0.013) \\
\end{array}$ & $\begin{array}{c}1.000 \\
(0.161)\end{array}$ & $\begin{array}{c}0.999 \\
(0.159) \\
\end{array}$ \\
\hline \multicolumn{10}{|c|}{ C. Indirect effect } \\
\hline$T_{d}$ & $\begin{array}{c}0.001 \\
(0.0002)\end{array}$ & $\begin{array}{c}0.220 \\
(0.061)\end{array}$ & $\begin{array}{c}0.183 \\
(0.077)\end{array}$ & $\begin{array}{c}0.002 \\
(0.001)\end{array}$ & $\begin{array}{c}0.457 \\
(0.283)\end{array}$ & $\begin{array}{c}0.568 \\
(0.464)\end{array}$ & $\begin{array}{c}0.001 \\
(0.0002)\end{array}$ & $\begin{array}{c}0.138 \\
(0.110)\end{array}$ & $\begin{array}{c}0.147 \\
(0.115)\end{array}$ \\
\hline \multicolumn{10}{|c|}{ D. Total effect } \\
\hline$T_{d}$ & $\begin{array}{c}0.109 \\
(0.014) \\
\end{array}$ & $\begin{array}{c}1.127 \\
(0.164) \\
\end{array}$ & $\begin{array}{c}1.121 \\
(0.184) \\
\end{array}$ & $\begin{array}{c}0.087 \\
(0.014) \\
\end{array}$ & $\begin{array}{c}1.135 \\
(0.270) \\
\end{array}$ & $\begin{array}{c}1.210 \\
(0.381) \\
\end{array}$ & $\begin{array}{c}0.107 \\
(0.013) \\
\end{array}$ & $\begin{array}{l}1.138 \\
(0.175)\end{array}$ & $\begin{array}{c}1.146 \\
(0.185)\end{array}$ \\
\hline$\lambda$ & $\begin{array}{c}0.041 \\
(0.006)\end{array}$ & $\begin{array}{c}0.829 \\
(0.155)\end{array}$ & $\begin{array}{c}0.698 \\
(0.194) \\
0.742 \\
(0.200) \\
\end{array}$ & $\begin{array}{c}0.082 \\
(0.033)\end{array}$ & $\begin{array}{l}1.106 \\
(0.531)\end{array}$ & $\begin{array}{l}1.256 \\
(0.670) \\
-1.061 \\
(1.426) \\
\end{array}$ & $\begin{array}{c}0.027 \\
(0.011)\end{array}$ & $\begin{array}{c}0.465 \\
(0.253)\end{array}$ & $\begin{array}{c}0.479 \\
(0.290) \\
0.352 \\
(0.317)\end{array}$ \\
\hline $\begin{array}{l}\text { Obs. } \\
\mathrm{R}^{2}\end{array}$ & $\begin{array}{c}18,864 \\
0.990\end{array}$ & $\begin{array}{c}18,900 \\
0.391\end{array}$ & $\begin{array}{c}18,900 \\
0.412\end{array}$ & $\begin{array}{c}18,864 \\
0.990\end{array}$ & $\begin{array}{c}18,900 \\
0.356\end{array}$ & $\begin{array}{c}18,900 \\
0.344\end{array}$ & $\begin{array}{c}18,864 \\
0.990\end{array}$ & $\begin{array}{c}18,900 \\
0.335\end{array}$ & $\begin{array}{c}18,900 \\
0.330\end{array}$ \\
\hline
\end{tabular}

Notes: Models [1] and [2] are estimated based on a panel fixed effects spatial autoregressive (SAR) [1] with lagged dependent variable -, model [3] is based on a spatial autoregressive model with auto regressive disturbances (SAC). The spatial weighting matrix for these models is based on bilateral trade between OECD countries (weighted by audience-specific interests), with zero diagonal. This corresponds to $\widetilde{\text { Trade }}_{i j}$, as expressed in eq. (7), replacing imports by total trade. Columns [4]-[6], and [7]-[9] are estimated analogously, using geographic distance and the number of flight connections as weighting matrices, respectively. All regressions control for the average weekly CPM of the US national internet market and the digital STRI for electronic transactions, and include day-of-the-week dummies, country-quarter dummies, holiday dummies, monthly dummies, a dummy for brexit, a dummy for the US elections and country-specific dummy for local general elections. Robust standard errors in parentheses. 
Table A3: EFFECT OF FACEBOOK ACCOUNTING RESTRUCTURING ON ONLINE AD PRICES (TRIMMED SAMPLE)

\begin{tabular}{lccccccccc}
\hline \hline & $(1)$ & $(2)$ & $(3)$ & $(4)$ & $(5)$ & $(6)$ & $(7)$ & $(8)$ & $(9)$ \\
& FE & POLS & POLS & GLS & POLS & POLS & GLS & non-SO & SO \\
\hline \multirow{2}{*}{$T_{d}$} & 1.093 & 1.077 & 0.094 & 0.211 & -1.960 & 0.031 & -0.113 & -0.011 & -2.436 \\
& $(0.134)$ & $(0.132)$ & $(0.011)$ & $(0.021)$ & $(0.200)$ & $(0.034)$ & $(0.155)$ & $(0.136)$ & $(0.475)$ \\
$\widetilde{T r a d e}_{i}$ SO & & & & & -0.908 & -0.029 & 1.787 & -1.244 & 0.513 \\
& & & & & $(0.078)$ & $(0.014)$ & $(0.460)$ & $(0.376)$ & $(1.038)$ \\
$T_{d} \times \widetilde{\text { Trade }}_{i}$ SO & & & & & 3.775 & 0.079 & 0.431 & 0.162 & 3.635 \\
& & & & & $(0.241)$ & $(0.042)$ & $(0.197)$ & $(0.174)$ & $(0.574)$ \\
Obs. & 12,600 & 12,600 & 12,312 & 12,600 & 12,600 & 12,312 & 12,600 & 6,650 & 5,950 \\
$\mathrm{R}^{2}$ & 0.642 & 0.659 & 0.990 & & 0.667 & 0.990 & & & \\
& & & & & & & & & \\
\hline \multirow{2}{*}{ Effect at Av( $\widetilde{\text { Trade }}_{i}$ SO } & & & & 1.077 & 0.094 & 0.234 & 0.116 & 0.572 \\
& & & & & $(0.059)$ & $(0.011)$ & $(0.022)$ & $(0.020)$ & $(0.048)$ \\
\hline \hline
\end{tabular}

Notes: All columns are based on a trimmed sample, restricted to all observations before 1st of June 2016. Model [1] is estimated using a fixed effects panel model, models [2] and [3] by pooled OLS - where model [3] includes 8 lags of the dependent variable in addition (as suggested by the AIC) - and model [4] by GLS. Models [5]-[7] include goods imports from countries with a sales office, weighted by country specific product interests, whereby [5] is estimated by POLS, [6] includes 8 lags of the dependent variable, and [7] is estimated by GLS. [8] and [9] are estimated by GLS for non non-SO and $\mathrm{SO}$ countries, respectively. All models control for the average weekly CPM of the US national internet market (not reported) and further include day-of-the-week dummies, quarterly dummies, holiday dummies, month-year dummies, a dummy for brexit, a dummy for the US elections. Models in [2]-[9] also include the OECD digital STRI, quarterly log GDP, and ICT usage. Standard errors clustered at the country level in parentheses. 


\section{B Structural Break Test and VAR analysis of Facebook Ad CPM Prices}

Table B1: StruCtural BREAK TEST FOR WEEKLY OECD CPM PRICES

\begin{tabular}{|c|c|c|c|c|c|c|c|c|c|}
\hline Country & \multicolumn{2}{|c|}{ Test I } & \multicolumn{2}{|c|}{ Test II } & Country & \multicolumn{2}{|c|}{ Test I } & \multicolumn{2}{|c|}{ Test II } \\
\hline Australia & 297.66 & 0.0000 & 35.42 & 0.0000 & Latvia & 327.26 & 0.0000 & 26.54 & 0.0000 \\
\hline Austria & 369.67 & 0.0000 & 6.06 & 0.1086 & Lithuania & 290.89 & 0.0000 & 32.07 & 0.0000 \\
\hline Belgium & 282.11 & 0.0000 & 37.36 & 0.0000 & Luxembourg & 330.77 & 0.0000 & 16.55 & 0.0009 \\
\hline Bulgaria & 296.00 & 0.0000 & 32.17 & 0.0000 & Malta & 416.62 & 0.0000 & 43.02 & 0.0000 \\
\hline Canada & 313.59 & 0.0000 & 1.27 & 0.7351 & Mexico & 233.03 & 0.0000 & 48.87 & 0.0000 \\
\hline Chile & 290.22 & 0.0000 & 3.99 & 0.2621 & Netherlands & 277.84 & 0.0000 & 41.37 & 0.0000 \\
\hline Croatia & 280.79 & 0.0000 & 31.53 & 0.0000 & New Zealand & 339.08 & 0.0000 & 22.67 & 0.0000 \\
\hline Cyprus & 287.19 & 0.0000 & 0.45 & 0.9308 & Norway & 283.16 & 0.0000 & 16.04 & 0.0011 \\
\hline Czech Republic & 285.51 & 0.0000 & 9.78 & 0.0205 & Poland & 312.74 & 0.0000 & 3.53 & 0.3171 \\
\hline Denmark & 289.38 & 0.0000 & 46.02 & 0.0000 & Portugal & 245.44 & 0.0000 & 9.87 & 0.0197 \\
\hline Estonia & 352.89 & 0.0000 & 18.77 & 0.0003 & Romania & 343.62 & 0.0000 & 20.46 & 0.0001 \\
\hline Finland & 307.04 & 0.0000 & 23.96 & 0.0000 & Slovakia & 287.73 & 0.0000 & 8.13 & 0.0433 \\
\hline France & 328.98 & 0.0000 & 35.24 & 0.0000 & Slovenia & 255.78 & 0.0000 & 39.36 & 0.0000 \\
\hline Germany & 340.70 & 0.0000 & 8.62 & 0.0348 & South Korea & 471.39 & 0.0000 & 15.98 & 0.0011 \\
\hline Greece & 260.35 & 0.0000 & 14.57 & 0.0022 & Spain & 335.71 & 0.0000 & 8.66 & 0.0342 \\
\hline Hungary & 313.42 & 0.0000 & 12.08 & 0.0071 & Sweden & 382.05 & 0.0000 & 7.00 & 0.0719 \\
\hline Iceland & 240.55 & 0.0000 & 88.77 & 0.0000 & Switzerland & 289.68 & 0.0000 & 13.55 & 0.0036 \\
\hline Ireland & 375.31 & 0.0000 & 7.05 & 0.0493 & Turkey & 327.04 & 0.0000 & 4.60 & 0.2034 \\
\hline Israel & 278.19 & 0.0000 & 9.63 & 0.0220 & United Kingdom & 298.03 & 0.0000 & 17.68 & 0.0005 \\
\hline Italy & 458.96 & 0.0000 & 26.92 & 0.0003 & United States & 326.85 & 0.0000 & 109.59 & 0.0000 \\
\hline Japan & 383.45 & 0.0000 & 21.90 & 0.0001 & & & & & \\
\hline
\end{tabular}

Table reports $\chi^{2}$ test statistic results and significance level for the test of the null hypothesis that the CPM do not vary over the subsamples defined by the break date, specified as on the 7th of March 2016 (day of the announcement of Facebook UK's accounting restructuring). Test I is based on a simple regression of the CPM weekly level on a constant, whereas Test II is based on a regression of the CPM weekly level on a constant, its own first lag and on the contemporaneous level of OECD CPM weighted average. Weights are given by the share of Facebook users registered as resident in a given country.

To test the validity of the structural break hypothesis around the 7 th of march 2016, we conduct a series of tests, on the country-specific time series of Facebook weekly CPM prices. Inspired by the narrative approach method introduced by Romer and Romer (1989), we proceed with a reduced-form VAR estimation of the CPM for country-specific audiences around the date of the announcement, where we use weekly averages instead of daily data. This takes into account the potential interdependence of country-specific advertising prices as suggested by the co-movement of the CPMs across different countries shown in Figure 2, as well as the time series nature of our data. The effects of the change in accounting practices can be illustrated by the corresponding impulse-response functions. 
Specifically, we account for exogenous stock prices, endogenous prices and the effect of (the lead of) After . We follow the AIC, and include only one lag. Thereby we constrain the lag parameter on the equation for After to zero, and make a small-sample degrees-of-freedom adjustment. The impulse response functions (IRF) for the effect of the accounting restructuring on median CPM prices across all OECD countries (see Figures B2, B3 and B4) are reported subsequently. As suggested by these figures and by the results on structural break tests, we find significant jumps after the announcement in March 2016, conditional on the series' lags, stock prices, and quarterly dummies. In order to be able to compare the intensity of the effect, we scale the axes homogeneously. Two things become evident from the figures: the announcement effect is not only significant statistically and economically, but it is also heterogeneous across different countries. For instance, we find very strong effects for the majority of EU countries with a sales office (see France, Germany, the Netherlands and Spain, from figure B2), and very small effects for the EU countries without a Sales Office. We also find that the effects are generally small for many countries which are a) smaller and/or less developed, and that b) levy lower corporate taxes. 

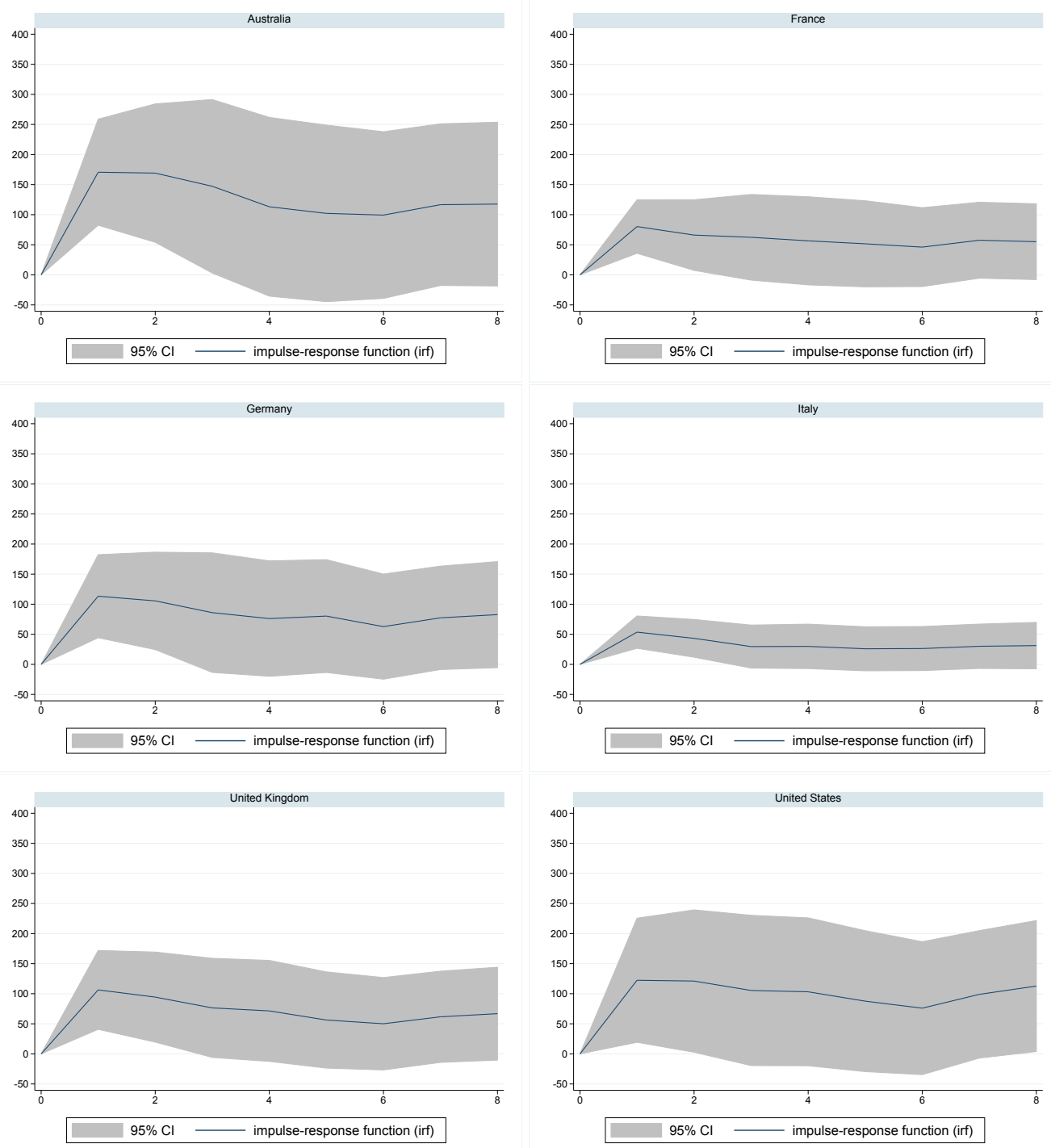

Figure B1: IMPULSE RESPONSE FUNCTIONS FOR THE EFFECT OF TAX ANNOUNCEMENT ON MEDIAN CPM PRICES FOR SELECTED OECD COUNTRIES Note: We estimate a reduced-form VAR model including one lag (chosen by AIC) as well as Facebook stock price and quarterly dummies as exogenous variables. The standard errors are corrected for small sample and degree-of-freedom adjusted. Data are based on weekly median CPM prices for all OECD countries. We model the tax announcement with one lead as an endogenous variable and constrain its lag parameter to zero. 

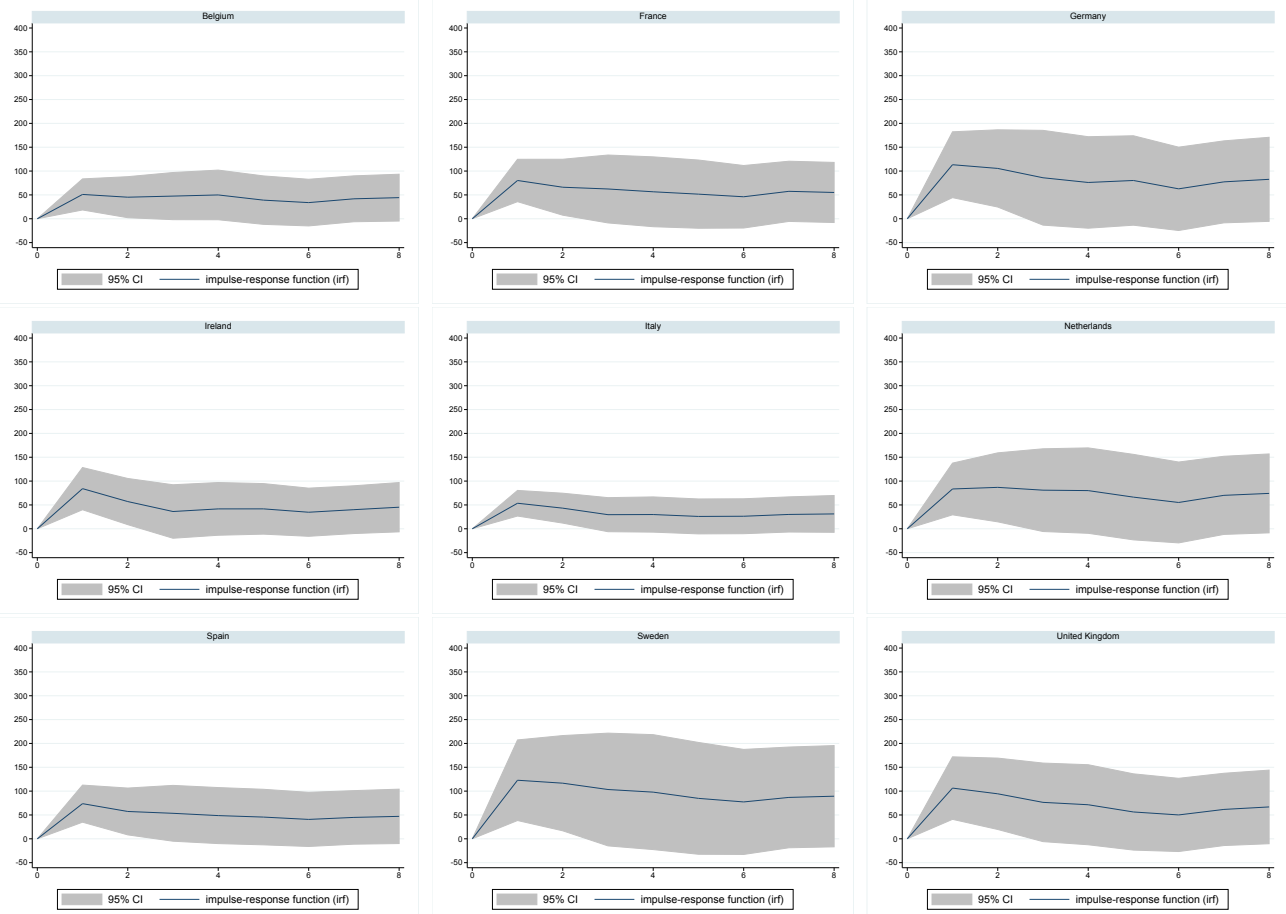

Figure B2: IMPULSE RESPONSE FUNCTIONS FOR THE EFFECT OF TAX ANNOUNCEMENT ON MEDIAN CPM PRICES ACROSS EU COUNTRIES WITH A SAles Office 

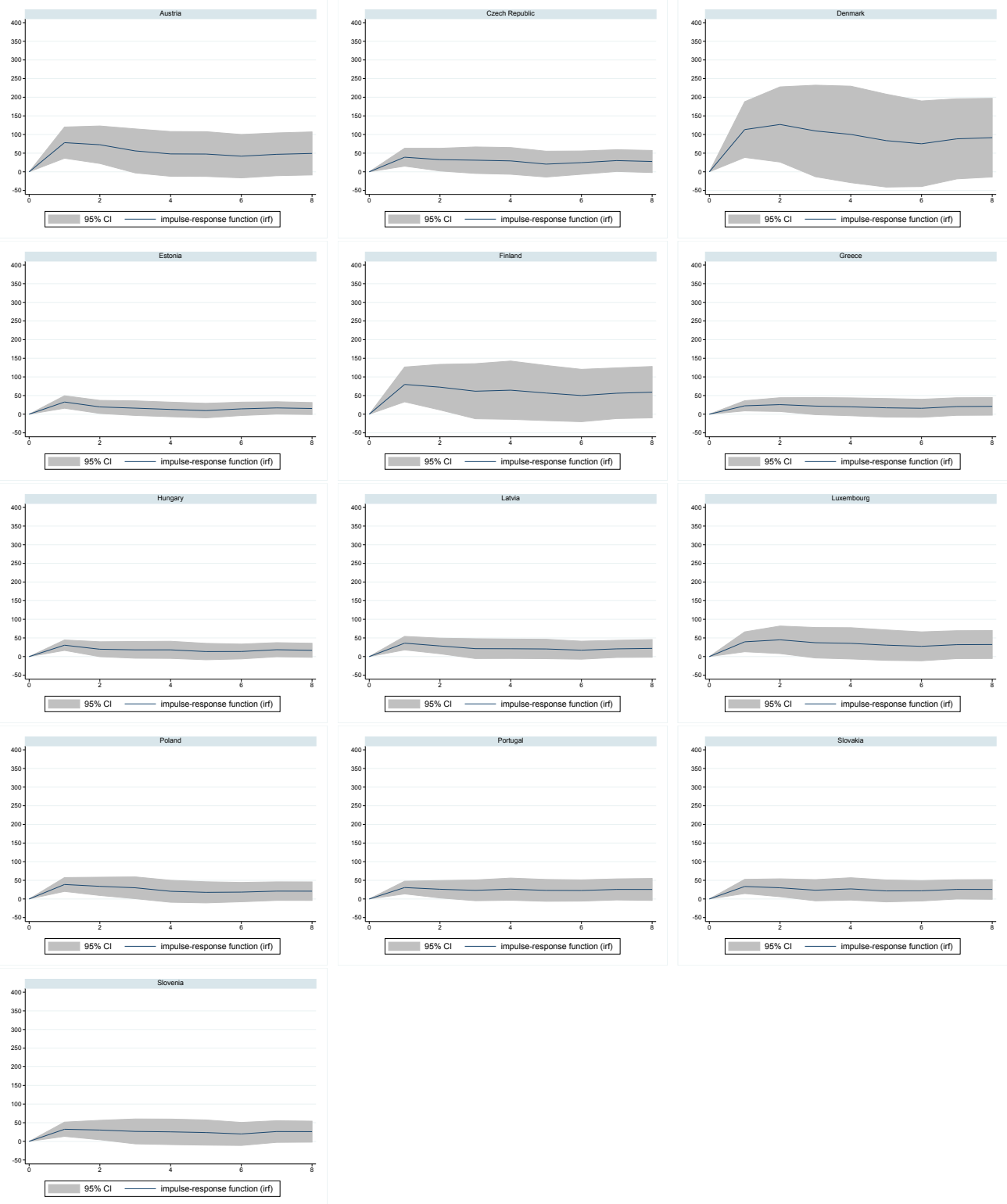

Figure B3: IMPULSE RESPONSE FUNCTIONS FOR THE EFFECT OF TAX ANNOUNCEMENT ON MEDIAN CPM PRICES ACROSS EU COUNTRIES WITHOUT A SALES OFFICE 
Countries with a Sales Office
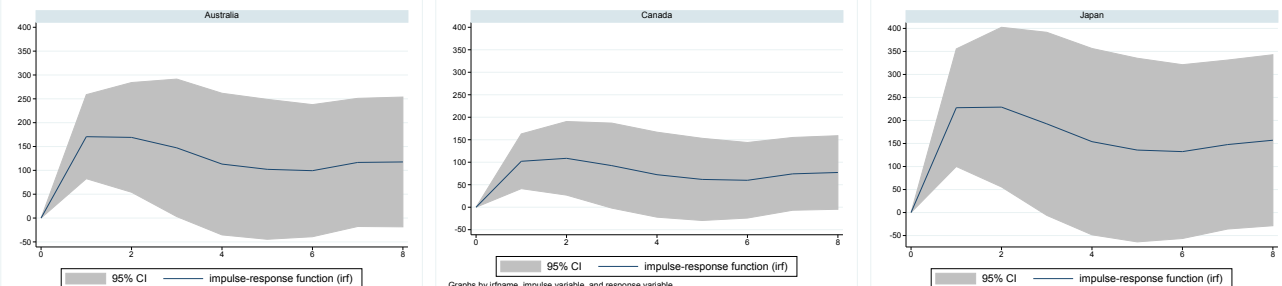

95\% C1 - impulse-response function (it)
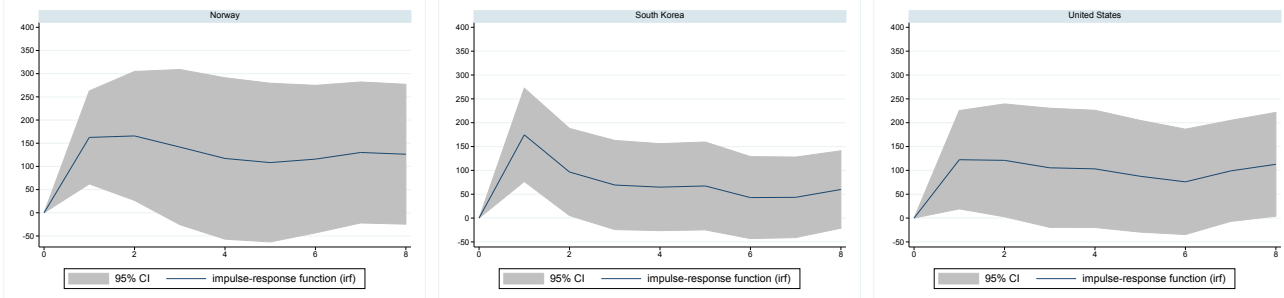

Countries without a Sales Office
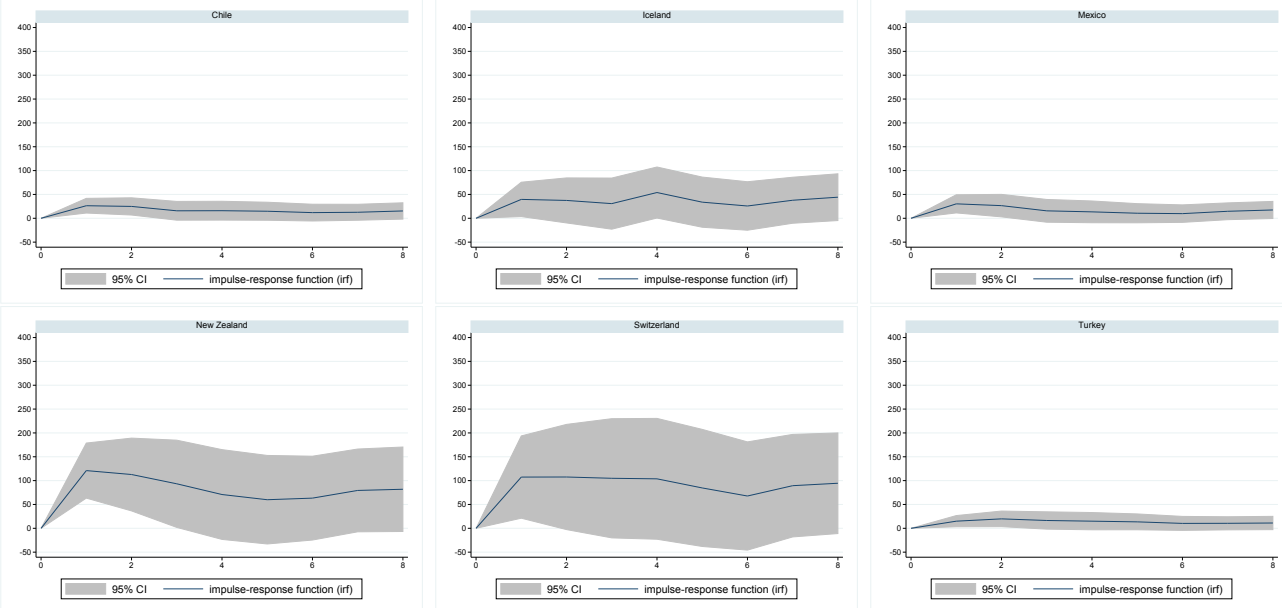

Figure B4: IMPULSE RESPONSE FUNCTIONS FOR THE EFFECT OF TAX ANNOUNCEMENT ON MEDIAN CPM PRICES ACROSS NON EU MEMBERS OF THE OECD

Note: We estimate a reduced-form VAR model including one lag (chosen by AIC) as well as Facebook stock price and quarterly dummies as exogenous variables. The standard errors are corrected for small sample and degree-of-freedom adjusted. Data are based on weekly median CPM prices for all OECD countries. We model the tax announcement with one lead as an endogenous variable and constrain its lag parameter to zero. 


\section{Proofs not given in the text}

Totally differentiating (2) and (3), we get, for , $i=1,2$,

$$
\frac{\partial q_{i 1}}{\partial t}=-\frac{\frac{\partial^{2} \pi}{\partial q_{i 1} \partial t} \frac{\partial^{2} \pi}{\partial q_{i 2}^{2}}-\frac{\partial^{2} \pi}{\partial q_{i 2} \partial t} \frac{\partial^{2} \pi}{\partial q_{i 1} \partial q_{i 2}}}{\frac{\partial^{2} \pi}{\partial q_{i 2}^{2}} \frac{\partial^{2} \pi}{\partial q_{i 1}^{2}}-\frac{\partial^{2} \pi}{\partial q_{i 1} \partial q_{i 2}} \frac{\partial^{2} \pi}{\partial q_{i 1} \partial q_{i 2}}}, \quad \frac{\partial q_{i 2}}{\partial t}=-\frac{\frac{\partial^{2} \pi}{\partial q_{i 2} \partial t} \frac{\partial^{2} \pi}{\partial q_{i 1}^{2}}-\frac{\partial^{2} \pi}{\partial q_{i 1} \partial t} \frac{\partial^{2} \pi}{\partial q_{i 1} \partial q_{i 2}}}{\frac{\partial^{2} \pi}{\partial q_{i 2}^{2}} \frac{\partial^{2} \pi}{\partial q_{i 1}^{2}}-\frac{\partial^{2} \pi}{\partial q_{i 1} \partial q_{i 2}} \frac{\partial^{2} \pi}{\partial q_{i 1} \partial q_{i 2}}} .
$$

We have $\frac{\partial^{2} \pi}{\partial q_{i 1}^{2}}, \frac{\partial^{2} \pi}{\partial q_{i 2}^{2}}<0$ and $\frac{\partial^{2} \pi}{\partial q_{i 2}^{2}} \frac{\partial^{2} \pi}{\partial q_{i 1}^{2}}-\frac{\partial^{2} \pi}{\partial q_{i 1} \partial q_{i 2}} \frac{\partial^{2} \pi}{\partial q_{i 1} \partial q_{i 2}}>0$ by the assumption that second order conditions are satisfied at equilibrium. Furthermore, we have

$$
\begin{array}{r}
\frac{\partial^{2} \pi}{\partial q_{i 1} \partial q_{i 2}}=z_{i}^{\prime} n_{2} n_{1}\left[\left(p_{i 2}+\frac{\partial p_{i 2}}{\partial q_{i 2}} q_{i 2}\right)+(1-t)\left(p_{i 1}+\frac{\partial p_{i 1}}{\partial q_{i 1}} q_{i 1}\right)\right]+ \\
+z_{i}^{\prime \prime} n_{2} n_{1}\left[(1-t) n_{1} p_{i 1} q_{1}+n_{2} p_{i 2} q_{i 2}\right]<0,
\end{array}
$$

The inequality follows from (2) and (3). Specifically, (2) and (3) equal zero in equilibrium. Given this, and because the terms $z_{i}^{\prime} q_{i j} p_{i j} n_{j}$ are negative, the terms in round parentheses above are positive. Furthermore, we have

$$
\frac{\partial^{2} \pi}{\partial q_{2} \partial t}=-z_{i}^{\prime} q_{i 1} p_{i 1} n_{1} n_{2}>0, \quad \frac{\partial^{2} \pi}{\partial q_{i 1} \partial t}=-n_{1}\left[z_{i}^{\prime} n_{1} q_{i 1} p_{i 1}+z_{i}\left(\frac{\partial p_{i 1}}{\partial q_{i 1}} q_{i 1}+p_{i 1}\right)\right]<0
$$

The last of these inequalities follows from (3). Given that $z_{i}^{\prime} q_{i 2} p_{i 2} n_{2}<0$ and $(1-t)>0$, we must have $z_{i}^{\prime} n_{1} q_{i 1} p_{i 1}+z_{i}\left(\frac{\partial p_{i 1}}{\partial q_{i 1}} q_{i 1}+p_{i 1}\right)>0$.

Given the above expressions, we get

$$
\frac{\partial q_{i 2}}{\partial t}>0 \Longleftrightarrow \frac{\partial^{2} \pi}{\partial q_{i 2} \partial t} \frac{\partial^{2} \pi}{\partial q_{i 1}^{2}}<\frac{\partial^{2} \pi}{\partial q_{i 1} \partial t} \frac{\partial^{2} \pi}{\partial q_{i 1} \partial q_{i 2}}
$$

and we find $\frac{\partial q_{i 2}}{\partial t}>0$ because $\frac{\partial^{2} \pi}{\partial q_{i 1} \partial t}<0$. Furthermore, we have

$$
\frac{\partial q_{i 1}}{\partial t}<0 \Longleftrightarrow \frac{\partial^{2} \pi}{\partial q_{i 1} \partial t} \frac{\partial^{2} \pi}{\partial q_{i 2}^{2}}>\frac{\partial^{2} \pi}{\partial q_{i 2} \partial t} \frac{\partial^{2} \pi}{\partial q_{i 1} \partial q_{i 2}}
$$

Again, $\frac{\partial q_{i 1}}{\partial t}<0$ because $\frac{\partial^{2} \pi}{\partial q_{i 1} \partial t}<0$. 


\section{Effect of tax change and pass-through by country}

Table D1: EFFECT AND PASS-THROUGH BY COUNTRY

\begin{tabular}{|c|c|c|c|c|c|}
\hline \multicolumn{6}{|c|}{ Countries with Sales Office } \\
\hline & & & \multicolumn{3}{|c|}{ Pass-through with IRE tax rate (\%) } \\
\hline & Initial & Effect & & & 12.5 \\
\hline AUS & 2.12 & 0.74 & 0.93 & 1.30 & 2.01 \\
\hline BEL & 0.73 & 0.29 & 1.06 & 1.49 & 2.31 \\
\hline CAN & 1.36 & 0.45 & 1.01 & 1.41 & 2.19 \\
\hline DEU & 1.50 & 0.56 & 0.99 & 1.39 & 2.16 \\
\hline ESP & 1.07 & 0.34 & 0.85 & 1.18 & 1.84 \\
\hline FRA & 0.78 & 0.33 & 1.12 & 1.57 & 2.44 \\
\hline UK & 1.82 & 0.40 & 0.59 & 0.82 & 1.28 \\
\hline ISR & 1.33 & 0.35 & 0.83 & 1.16 & 1.81 \\
\hline ITA & 0.78 & 0.16 & 0.77 & 1.08 & 1.68 \\
\hline JPN & 2.72 & 1.09 & 1.07 & 1.49 & 2.32 \\
\hline KOR & 2.37 & 0.65 & 0.85 & 1.19 & 1.84 \\
\hline NLD & 1.00 & 0.47 & 1.24 & 1.74 & 2.70 \\
\hline NOR & 1.46 & 0.80 & 1.46 & 2.04 & 3.17 \\
\hline NZL & 1.09 & 0.40 & 1.40 & 1.96 & 3.05 \\
\hline $\mathrm{POL}$ & 0.29 & 0.12 & 1.67 & 2.34 & 3.64 \\
\hline SWE & 1.57 & 0.29 & 0.72 & 1.01 & 1.57 \\
\hline USA & 2.43 & 0.57 & 0.74 & 1.03 & 1.61 \\
\hline Average & 1.37 & 0.46 & 1.03 & 1.42 & 2.22 \\
\hline \multirow{2}{*}{\multicolumn{6}{|c|}{ Countries without Sales Office }} \\
\hline & & & & & tax rate $(\%)$ \\
\hline & Initial & Effect & 0 & 6.25 & 12.5 \\
\hline & CPM & $\mathrm{Td}$ & & & \\
\hline AUT & 0.93 & 0.26 & 1.08 & 1.52 & 2.35 \\
\hline $\mathrm{CHE}$ & 1.45 & 0.30 & 0.79 & 1.11 & 1.72 \\
\hline $\mathrm{CHL}$ & 0.40 & 0.07 & 0.68 & 0.95 & 1.48 \\
\hline $\mathrm{CZE}$ & 0.27 & 0.17 & 2.38 & 3.33 & 5.17 \\
\hline DNK & 1.25 & 0.33 & 1.02 & 1.42 & 2.21 \\
\hline EST & 0.21 & 0.12 & 2.28 & 3.20 & 4.96 \\
\hline FIN & 0.68 & 0.27 & 1.55 & 2.17 & 3.38 \\
\hline GRC & 0.20 & 0.06 & 1.27 & 1.78 & 2.77 \\
\hline HUN & 0.19 & 0.07 & 1.51 & 2.11 & 3.28 \\
\hline IRL & 1.07 & 0.21 & 0.76 & 1.06 & 1.65 \\
\hline ISL & 0.28 & 0.22 & 3.07 & 4.30 & 6.67 \\
\hline LTU & 0.18 & 0.09 & 1.98 & 2.77 & 4.30 \\
\hline LUX & 0.57 & 0.13 & 0.86 & 1.21 & 1.87 \\
\hline LVA & 0.27 & 0.13 & 1.77 & 2.48 & 3.85 \\
\hline MEX & 0.57 & 0.08 & 0.54 & 0.75 & 1.17 \\
\hline PRT & 0.29 & 0.12 & 1.63 & 2.28 & 3.53 \\
\hline SVK & 0.31 & 0.12 & 1.50 & 2.10 & 3.26 \\
\hline SVN & 0.23 & 0.11 & 1.88 & 2.64 & 4.09 \\
\hline TUR & 0.23 & 0.06 & 0.96 & 1.34 & 2.08 \\
\hline Average & 0.52 & 0.14 & 1.42 & 2.03 & 3.15 \\
\hline
\end{tabular}

\section{E Model, calibration and data for the wel- fare analysis}

We consider the setup of Section 4.3 , with $N>2$ countries. Let $M_{i}$ be the population of potential users in country $i$. A user in $i$ gains the following 
utility from browsing the platform

$$
U_{i}(m)=1-\alpha_{i} q_{i}-m,
$$

where $m$ is distributed uniformly on the $[0,1]$ interval. Recall that $q_{i}=$ $\sum_{j=1 . . N} n_{j} q_{i j}$ is the total quantity of ads the consumer is exposed to. Users connect to the platform only if they get a positive utility. Given our assumptions, the quantity of users in $i$ who connect is $M_{i} z_{i}=M_{i}\left(1-\alpha_{i} q_{i}\right)$. It follows that the aggregate surplus of $i$ 's consumers is

$$
C S_{i}=M_{i}\left(1-\alpha_{i} q_{i}\right)^{2} / 2
$$

We specify the inverse demand for impressions to a consumer in $i$ by an advertiser in country $j$ as

$$
p_{i j}\left(q_{i j}\right)=\beta_{j}-\gamma_{j} q_{i j}
$$

The aggregate surplus of advertisers from country $j$ is

$$
A S_{j}=n_{j} \sum_{i=1 . . N} M_{i} z_{i} \frac{\left(\beta_{j}-p_{i j}\right) q_{i j}}{2} .
$$

We denote by $t_{j}$ the tax rate set by country $j$ on the revenue the platform collects in its jurisdiction. The platform's tax payment in country $j$ is therefore

$$
T_{j}=n_{j} t_{j} \sum_{i=1 . . N} M_{i} z_{i} p_{i j} q_{i j},
$$

and the platform's profit in country $j$ is

$$
\pi_{j}=\left(1-t_{j}\right) n_{j} \sum_{i=1 . . N} M_{i} z_{i} q_{i j} p_{i j}
$$

We define welfare in country $i$ as the sum of consumer and advertiser 
surplus, the platform's profit and tax revenue:

$$
W_{i}=\pi_{i}+C S_{i}+A S_{i}+T_{i}
$$

We use data from the period before Facebook's accounting change, i.e. from July 2015 to March 2016. The data described in the previous sections are enhanced with information on the exposure to ads on Facebook stemming from an experimental dataset (Cabañas et al., 2017). The latter reports information about the average number of impressions that a sample of Facebook users in each country is exposed to while browsing the social media website ${ }^{42}$ As Table E1 reports, each user sees about two ads per minute on average, with users in Mexico being exposed to the lowest quantity of ads, and users in Germany, the UK and the US being exposed to the largest quantity. We use these quantities to approximate the exposure to ads, $q_{i}$, in the model. (Note that we do not observe the advertisers' location.)

To obtain the disutility parameter $\alpha_{i}$ in expression (E.1), we combine information on the share of daily active users in each country with information on exposure to ads. Specifically, we approximate the share of platform users, $z_{i}$, by the ratio of daily users and the total number of users in each country, as reported by Facebook's Ad Manager. We then combine this information with $q_{i}$ to obtain $\alpha_{i}$, based on (E.1).

We calibrate the parameters of the demand function in expression (E.3) given the assumption that they do not vary according to which audience advertisers from country $j$ target. It is not possible to differentiate such parameters by target country because, recall, we do not observe the quantities $q_{i j}$ and the prices $p_{i j}$. We compute the slope, $\gamma_{j}=\partial p_{i j} / \partial q_{i j}$, starting

\footnotetext{
${ }^{42}$ The dataset was collected through a Facebook plugin, the FDVT (https://fdvt. org/).
} 
from the elasticity of demand for ads $\epsilon_{q p}^{i j}$

$$
\epsilon_{q p}^{i j}=\frac{\partial q_{i j}}{\partial p_{i j}} \frac{p_{i j}}{q_{i j}} \Longrightarrow \gamma_{j}=\left(1 / \epsilon_{q p}^{i j}\right) \frac{p_{i j}}{q_{i j}}
$$

We approximate $q_{i j}$ by taking the quantity of ads that users in country $j$ are exposed to (described above) and dividing it by the total number of advertisers. For each country $j$, we approximate for $q_{i j}$ using information about the total number of advertisers on Facebook and each country's share of global GDP in 2015 as well as businesses' propensity to advertise online. ${ }^{43}$ We approximate for target-specific ad prices, $p_{i j}$, by the median price for advertising to country $j, p_{j}$. This assumption is consistent with the idea that domestic advertisers should have a large weight in determining the price of ads in country $j$. As we report in Table E1, there is substantial variation in such prices across the countries we consider. The highest price is for ads targeting audiences in Japan (CPM \$2.58) and lowest to Mexico (CPM \$0.58). Finally, because we lack information on the elasticity of demand by advertisers on Facebook, we use the average of the estimates in Argentesi and Filistrucchi (2007, Table 4) for newspaper advertising, i.e. -0.84. Having obtained the estimate for $\gamma_{j}$, we compute $\beta_{j}$ based on E.3.

\footnotetext{
${ }^{43}$ According to Statista.com, the total number of advertisers on Facebook at the end of 2015 was approximately 3 million globally. We calculate the approximate share of such advertisers from each country based on each country's share of global GDP, weighted by the average of four variables that describe a country's firms' propensity to operate (and, thus, advertise) online. These variables are: (i) the share of businesses with a website or home page, (ii) the share of businesses with a website allowing for ordering or reservation (iii) the share of businesses receiving orders through the internet and (iv) the share of businesses using social media. This information is available from the OECD (https://stats.oecd.org/).
} 
Table E1: DATA AND PARAMETERS FOR WELFARE ANALYSIS

\begin{tabular}{|c|c|c|c|c|}
\hline & Daily users ('000) & Ads per user-hour & Median CPM (\$cent) & Advertisers \\
\hline GER & 20,884 & 134.6 & 142.5 & 91,700 \\
\hline FRA & 22,215 & 115.2 & 70.0 & 53,600 \\
\hline UK & 29,062 & 138.4 & 174.5 & 84,600 \\
\hline JPN & 13,715 & 100.4 & 258.9 & 167,400 \\
\hline MEX & 44,559 & 85.9 & 58.5 & 30,800 \\
\hline \multirow[t]{2}{*}{ USA } & 144,871 & 131.5 & 246.8 & 801,200 \\
\hline & Tax rate $(\%)$ & $\alpha$ & $\beta$ & $\gamma$ \\
\hline GER & 29.8 & 0.14 & 0.31 & 0.08 \\
\hline FRA & 34.4 & 0.17 & 0.15 & 0.04 \\
\hline UK & 19.0 & 0.08 & 0.38 & 0.07 \\
\hline JPN & 29.7 & 0.34 & 0.57 & 0.22 \\
\hline MEX & 30.0 & 0.32 & 0.13 & 0.06 \\
\hline USA & 25.8 & 0.11 & 0.54 & 0.12 \\
\hline
\end{tabular}

The total quantity and median prices of ads we obtain in the pre-tax scenario are very close to the observed ones, see the last columns (TOT) of the top panels of tables E2 and E3. The majority of ads consumers are exposed to come from the US and UK. These countries are also the ones where advertisers tend to pay the highest prices, together with Japan.

In the post-tax regime, the platform pays the corporate tax rate on revenue generated in all SO countries. We obtain an increase of about 20 percent in the prices paid by advertisers from countries where the tax rate increased, while the quantity of ads mildly decreases, by about two to three percent. The model also predicts a decrease in the prices paid by advertisers from US and Mexico, although this decrease is rather small in magnitude. Overall, the median price per audience (computed as the weighted average of the ad prices to reach a given audience) increases by about 20 percent to target audiences in SO countries where the effective tax rate goes up, and by a smaller extent for audiences in the US and Mexico. See the bottom panels of tables E2 and E3. 
Table E2: AD IMPREssions PER USER

\begin{tabular}{lrrrrrrr}
\hline \hline \multicolumn{4}{c}{ Ad impressions (per user-hour), Pre-Tax Scenario } \\
\hline to/from & GER & FRA & UK & JPN & MEX & USA & TOT \\
GER & 22.0 & 16.3 & 31.1 & 14.6 & 9.2 & 35.0 & 128.2 \\
FRA & 21.4 & 15.2 & 30.4 & 14.4 & 8.5 & 34.4 & 124.2 \\
UK & 23.2 & 18.4 & 32.4 & 15.0 & 10.7 & 36.0 & 135.8 \\
JPN & 17.7 & 8.7 & 26.2 & 13.1 & 4.0 & 31.2 & 100.9 \\
MEX & 18.1 & 9.5 & 26.7 & 13.2 & 4.6 & 31.6 & 103.6 \\
USA & 22.6 & 17.4 & 31.8 & 14.8 & 10.0 & 35.5 & 132.1 \\
\hline
\end{tabular}

Ad impressions (per user-hour), Post-Tax Scenario

\begin{tabular}{lrrrrrrr}
\hline to/from & GER & FRA & UK & JPN & MEX & USA & TOT \\
GER & 21.2 & 14.8 & 30 & 13.6 & 10.2 & 36.4 & 126.2 \\
FRA & 20.2 & 12.4 & 29.6 & 13 & 9.8 & 36 & 121 \\
UK & 21 & 16.4 & 31.6 & 14.2 & 11.4 & 36.8 & 131.4 \\
JPN & 15.4 & 4.8 & 25.2 & 12 & 5.8 & 34 & 97.2 \\
MEX & 17.1 & 6.6 & 26.4 & 11.0 & 5.9 & 32.6 & 99.6 \\
USA & 20.8 & 15.2 & 30.2 & 13.4 & 10.4 & 37.0 & 127.0 \\
\hline \hline
\end{tabular}

Table E3: AD PRICES

\begin{tabular}{lrrrrrrr}
\hline \hline \multicolumn{7}{c}{ Ad prices (CPM, \$cent), Pre-Tax Scenario } \\
\hline to/from & GER & FRA & UK & JPN & MEX & USA & AVG \\
GER & 119.5 & 68.1 & 132.2 & 175.2 & 57.2 & 180.4 & 140.6 \\
FRA & 67.9 & 51.9 & 74.9 & 93.9 & 49.9 & 90.9 & 70.4 \\
UK & 120.1 & 64.1 & 165.2 & 211.1 & 57.1 & 200.6 & 168.0 \\
JPN & 176.5 & 112.5 & 204.5 & 280.5 & 104.5 & 268.5 & 254.8 \\
MEX & 65.2 & 78.8 & 67.3 & 57.8 & 76.2 & 55.1 & 59.7 \\
USA & 160.5 & 84.5 & 193.8 & 284.0 & 75.0 & 269.8 & 246.1 \\
\hline
\end{tabular}

Ad prices (CPM, \$cent), Post-Tax Scenario

\begin{tabular}{lrrrrrrr}
\hline to/from & GER & FRA & UK & JPN & MEX & USA & AVG \\
GER & 184.2 & 105.8 & 195.2 & 230.4 & 51.2 & 171.5 & 171.3 \\
FRA & 95.1 & 78.4 & 102.6 & 140.2 & 42.3 & 78.4 & 82.5 \\
UK & 175.4 & 79.6 & 225.1 & 271.3 & 51.0 & 190.4 & 207.5 \\
JPN & 235.1 & 142.1 & 275.6 & 361.3 & 94.2 & 262.1 & 308.4 \\
MEX & 80.4 & 93.2 & 96.1 & 80.4 & 62.3 & 48.2 & 60.9 \\
USA & 220.5 & 110.5 & 245.6 & 369.4 & 72.9 & 252.3 & 251.9 \\
\hline \hline
\end{tabular}




\section{F Advertising Auctions on Facebook}

To allocate advertising opportunities on its website, Facebook adopts an auction system based on the Vickrey-Groves-Clark (VCG) mechanism. We present this mechanism in an informal way. Consider an auction where a set of goods is being sold. In the case of Facebook, these goods correspond to advertising space on the "wall" of a set of users defined by certain characteristics (e.g., demographics, interests, etc.), i.e. an audience. For each of these goods, bidders (advertisers) announce the maximum price they are willing to pay. Bidders cannot see other participants' bids (sealed-bid auction). The auction closes once all the bids are in.

In the standard VCG auction, the auctioneer calculates for each bid the marginal loss to the other bidders if the bid were successful. For those who would have obtained the goods if the bid in question were ignored, the loss is equal to the bid they placed (i.e., their declared willingness to pay). The loss is instead zero to all bidders who would not have obtained the good, even if the bid considered were ignored. The auctioneer allocates the good to the highest bidders and charges them the marginal loss their bid has caused to others.

To fix ideas, suppose there is only one good to be allocated. In this case, the auction system would allocate the good to the highest bidder, and charge the second-highest bid (i.e., the loss to the bidder who would have received the good otherwise) to the winner. That is, the mechanism reduces to a second-price auction when a single good is for sale.

It can be shown that this mechanism maximizes the aggregate utility of bidders, since all the goods are attributed to the participants with the highest willingness-to-pay. Furthermore, if agents are fully rational and in the absence of collusion, the willingness to pay is reported truthfully. This is because only the marginal harm to other bidders will be charged to each 
participant, making truthful bidding a (weakly) dominant strategy. However, this type of auction does not maximize the seller's revenue. According to Facebook, though, this disadvantage is unimportant. The reason is that, although some revenue may be sacrificed in the short run, in the long run the mechanism improves the relevance of the ad to the selected audience and, therefore, the effectiveness of advertising on the platform.

Facebook's auction system is in fact more complex than the standard VCG auction, because it considers not only the marginal loss to other bidders (advertisers), but also the loss to the users who get exposed to the ads. Although the company does not disclose the details of this procedure, we can summarily describe it as follows. For a given audience, Facebook calculates a relevance score associated to each ad proposed by the respective bidders. The higher this score, the higher the imputed loss to the audience when that advertiser's bid is unsuccessful. The score captures the cost to the audience of not seeing the ad. Facebook uses the relevance score to determine which bids are successful and how much the winners should be charged (that is, the size of the combined loss on users and other advertisers). This process is controlled by a Facebook automated algorithm, which is not observed by the researcher nor by the advertiser 44

According to Facebook, this system minimizes the probability that ads are shown to uninterested audiences. Furthermore, it increases the price advertisers should expect to pay when attempting to reach an audience that is also targeted by other relevant ads. Furthermore, less relevant ads cause higher "social" harm, so the price the advertiser pays increases as well.

\footnotetext{
${ }^{44}$ see https://www.facebook.com/business/help/430291176997542?helpref=faq content
} 


\section{G Collection of Facebook data}

Our main source of information is Facebook's Ad Manager website. ${ }^{45}$ This website provides an interface that advertisers can use to place ads on Facebook.

An advertiser using the Ad Manager selects an audience, defined by any combination of geographical location, demographical characteristics, personal interests and behaviors. The advertiser also selects a compensation method: CPM, CPC or CPA. Cost per Mille (CPM), is the unit price paid every time the ad is shown a thousand times to users in the selected audience. Advertisers who care for driving traffic to a specific web-page generally prefer to pay per click by the selected audience. This compensation method is referred to as Cost per Click (CPC). Finally, Cost per Action is a price paid every time a consumer adopts a certain action (e.g., visiting the advertiser's webpage).

The advertiser can then choose a maximum bid for impressions on that audience. In the latter case, Facebook displays a suggested bid range. The range of suggested bids indicates a minimum, a median and a maximum bid. According to Facebook, this is the range of prices that are currently being paid by advertisers winning auctions for the selected audience ${ }^{46}$ See Figure G2 for a screenshot of the page reporting the bid range. We queried the Ad Manager to collect the bid range for audiences defined exclusively by country of residence, for all OECD countries, using CPM, CPC and CPA metrics. The queries took place for every 15 minutes during our period of observation. We averaged the data at daily level.

The Ad Manager also provides advertisers with information about the expected size of the audience they intend to reach. Specifically, the website reports the expected number of daily active users that belong to the

\footnotetext{
${ }^{45}$ https://www.facebook.com/business/learn/facebook-ads-reporting-ads-manager

${ }^{46}$ See https://www.facebook.com/help/213140778716849.
} 
selected audience. See Figure G1. We also queried the website to collect information about the number of users in each country that are interested in certain products. Specifically, based on Comtrade's HS8-classification for categories of goods, we select audiences based on country of location and interest in each category, and collect the number of users within the audience so defined. Because our trade data is available at the yearly level, we average our information about country-product audiences yearly as well. We then compute the share of Facebook users within a country that are interested in each product category, thereby obtaining our vectors of penetration rates.

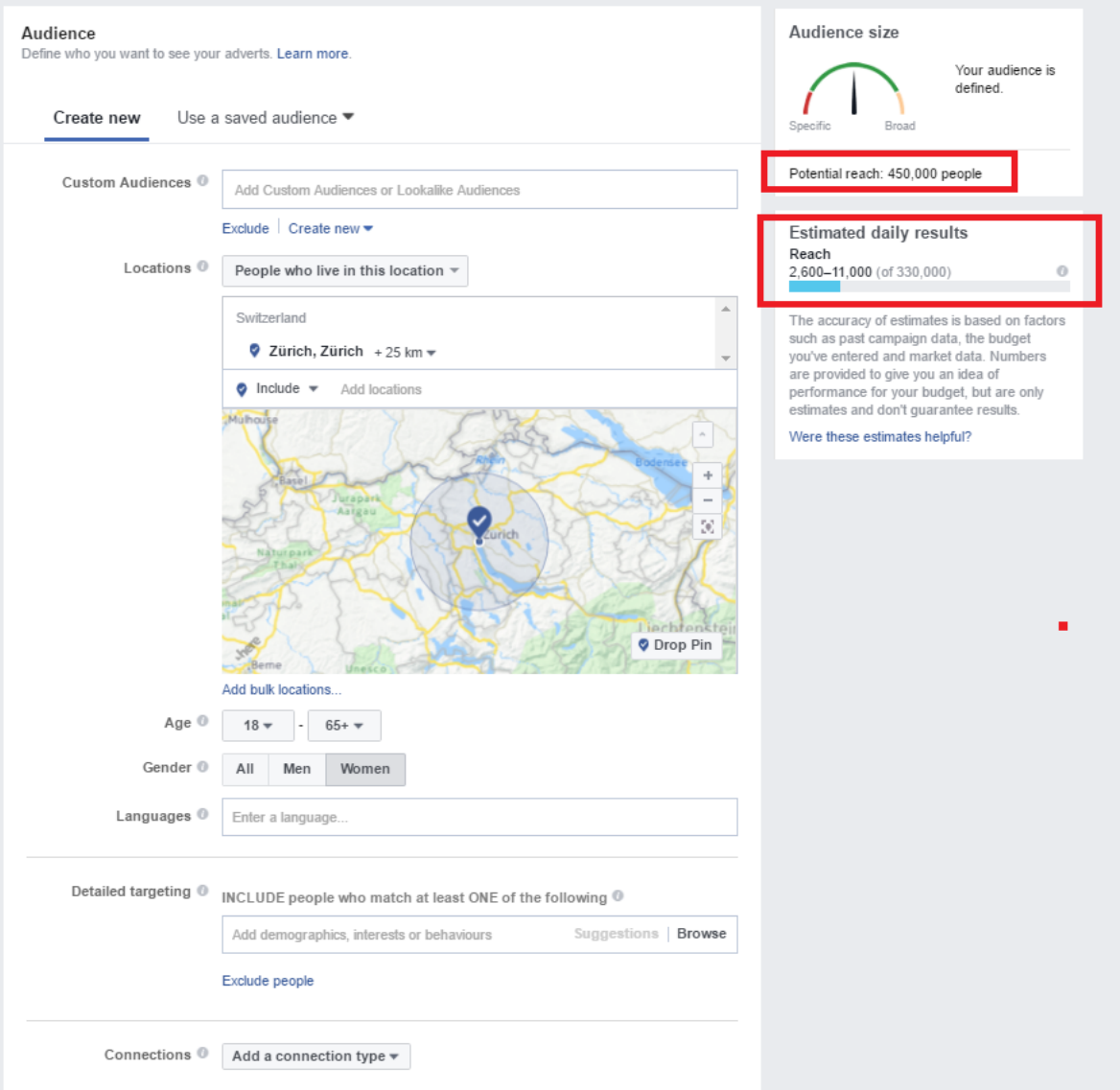

Figure G1: FACEBOOK AD MANAGER - SCREENSHOT 


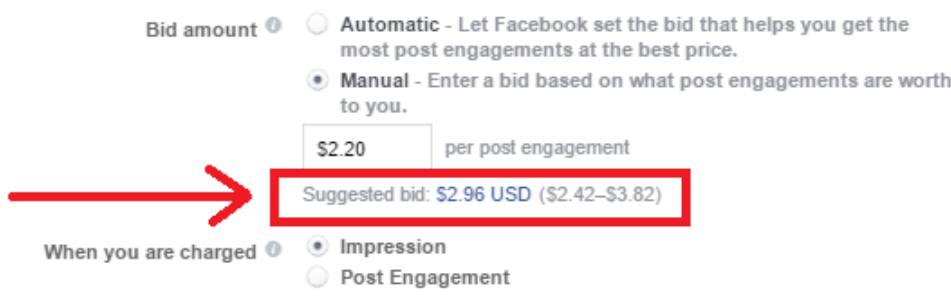

Figure G2: FACEBOOK AD SUGGESTED BID - SCREENSHOT 